\title{
PARA BENEFICIAR LA PLATA: MANO DE OBRA, PAPEL, Y POSICIÓN SOCIAL EN UNA REFINERÍA DE PLATA DURANTE EL PRIMER SIGLO DEL IMPERIALISMO ESPAÑOL EN EL PUEBLO DE PORCO
}

\author{
Brendan J. M. Weaver ${ }^{a}$
}

\begin{abstract}
Resumen
Antes de la conquista española, el pueblo de Porco, en el departamento de Potosí, Bolivia, fue uno de los asientos mineros más importante de los incas. Durante el virreinato, fue el foco de las primeras operaciones de minería de plata española en los Andes. Esta región ofrece una excelente oportunidad para que la arqueologia histórica plantee preguntas acerca de la relación entre los estados que organizaban dichos proyectos mineros y los trabajadores que explotaban el mineral, que nos ayuden a entender esa dinámica que tuvo un profundo impacto en los origenes de la economía andina moderna. Este artículo presenta evidencia arqueológica y etnohistórica para examinar la organización de ciertas categorias laborales coloniales, y el desarrollo de los papeles y posiciones sociales de trabajadores asociados a la industria minera andina sur-central para trazar la transición de la mano de obra en la región del imperio de los incas al de los españoles. Las excavaciones en el sitio colonial de Ferro Ingenio, una refinería de plata en el valle de San Juan, al sudoeste del pueblo de Porco, arrojan nuevas luces sobre el tema de la mano de obra en el primer siglo de colonialismo español y de cómo los trabajadores calificados negociaban sus propias posiciones en la sociedad colonial.
\end{abstract}

Palabras clave: mano de obra, economía politica, cultura material, minería colonial, yanacona

\section{Abstract \\ PARA BENEFICIAR LA PLATA: LABOR, ROLE, AND STATUS IN A SILVER REFINERY DURING THE FIRST CENTURY OF SPANISH IMPERIALISM IN THE TOWN OF PORCO}

Before the Spanish conquest, the town of Porco, in the Department of Potosi in modern-day Bolivia, was the site of one of the most important Inca mining projects. During the viceregal period it became the focus of the first Spanish silver mining operations of the in the Andes. This region offers an excellent opportunity for historical archeology to ask questions about the relationship between the states that organized such mining projects and the workers who exploited the ore. Such an undertaking grants us a better understanding of the dynamics that had a profound impact on the origins of the modern Andean economy. This article presents ethnohistorical and archaeological evidence in order to discuss the organization of colonial labor categories, and the development of the changing social roles and status of skilled workers associated with the south-central Andean mining industry. In doing so, I trace the regional transitions in labor from the Inca to Spanish empires. Excavations at the colonial site of Ferro Ingenio, a silver refinery in the San Juan Valley, southwest of the village of Porco, shed new light on labor in the first century of Spanish colonialism and how skilled indigenous workers negotiated their positions within colonial society.

Keywords: labor, political economy, material culture, colonial mining, yanacona

${ }^{a}$ Departamento de Historia, Berea College

Correo electrónico: weaverb@berea.edu 
«Beneficio de metal: A la gruesa o cantidad de metales que una persona beneficia de una vez se dice beneficio, si no lo tiene ordinario y corrido todo el año sin dejar de beneficiar, y así, tener un beneficio que hacer de tal partida de metal es tenerlo para beneficiar. Y propiamente es beneficio el que se le hace al metal desde que hecho harina y cernido se echa en el cajón, hasta que se lava en la tina para sacar la plata de él, y se hace así [...]»

García de Llanos (1983 [1609]: 12,13)

\section{Introducción}

El concepto de «beneficio de plata», en relación con el proyecto minero colonial de la región andina, es complejo y su significado múltiple. Como sugiere García de Llanos en la cita anterior de su diccionario minero de principios del siglo XVII, «beneficiar» se refiere tanto al acto físico de refinar metales como de recibir un beneficio económico y social de esa actividad (1983 [1609]: 12,13). Quizás con ironía, cuando se examina en términos de su impacto social más amplio, la villa imperial de Potosí y su famoso Cerro Rico hicieron fortuna para unos pocos privilegiados por el crecimiento del Imperio español, pero el costo humano de este «beneficio» fue espantoso. Las malas condiciones del trabajo metalúrgico y minero en Potosí colonial han sido bien documentadas (Capoche 1959 [1585]; Assadourian 1966; Bakewell 1984; Cole 1985; Tandeter 1992; Robins 2011). Esclavos importados de África trabajaban en turnos excesivamente severos en las refinerías e ingenios, y mingas (trabajadores asalariados) y mitayos, al servicio de la mita ${ }^{1}$, sumieron los grandes riesgos de las minas.

Mientras que la evidencia sugiere que las minas de Potosí no pudieron haber sido tan atroces como en otros asientos mineros en las Américas espańolas, por ejemplo, en Huancavelica (Bakewell 1984: 151), las minas potosinas cobraron cientos de vidas cada año en accidentes mineros, además de un número desconocido de casos de agotamiento y enfermedades crónicas (ibid.: 146). Sin embargo, en los últimos ańos, la etnohistoria ha brindado valiosa información sobre la experiencia cotidiana de la diversidad de pobladores que habitaron Potosí, y cómo negociaron el sistema colonial en una de las ciudades más grandes del mundo y que tuvo, a su vez, los mercados más abastecidos del virreinato en ese entonces (v.g. Mangan 2003, 2005). Por ejemplo, las vendedoras del mercado aprovecharon su posición como intermediarias para acceder a mejores bienes y un mejor estatus. Por su parte, los mitayos pagaban a los mingas para trabajar sus turnos en las minas, mientras ellos perseguían otras oportunidades en la ciudad, y los africanos libertos con habilidades calificadas en demanda encontraron empleo en las tiendas urbanas. Este artículo explora la arqueología de un subconjunto pequeño de trabajadores calificados a finales del siglo XVI y principios del XVII en Porco, al interior del distrito minero de Potosí. Dichos trabajadores, a pesar de los riesgos para su salud y la subyugación por parte del sistema colonial, redefinieron sus papeles sociales y renegociaron su posición social, a través de las oportunidades presentes, en su participación como agentes activos en la refinación de plata.

Porco, Bolivia, fue el asiento inca de un importante proyecto minero de plata y el foco de un culto dedicado al sol. Debido a su gran calidad y a su carácter sagrado, la plata de Porco fue utilizada para adornar el Templo del Sol, el Koricancha, en Cuzco (Cieza de León 1984 [1553]: 372). Asumido el control por los hispanos en 1538, Porco fue el primer centro de operaciones españolas de minería de plata en los Andes, pero cayó en una relativa oscuridad a finales del siglo XVI, cuando la cercana Veta Rica de Potosí, descubierta en 1545, adquirió mayor importancia (Fig. 1). Durante dos temporadas $(2006,2007)$, llevé a cabo prospecciones y excavaciones arqueológicas en el sitio de Ferro Ingenio, situado en la orilla sur del río San Juan, a siete kilómetros al suroeste del pueblo de Porco (Fig. 2). Este sitio colonial de procesamiento de plata fue usado y ocupado varias veces desde el siglo XVI, hasta principios de la época republicana boliviana, para beneficiar el metal de las minas cercanas del cerro Sora Sora. De ese modo, durante la ocupación más temprana del Ferro Ingenio, un pequeño grupo de especialistas indígenas — probablemente, 


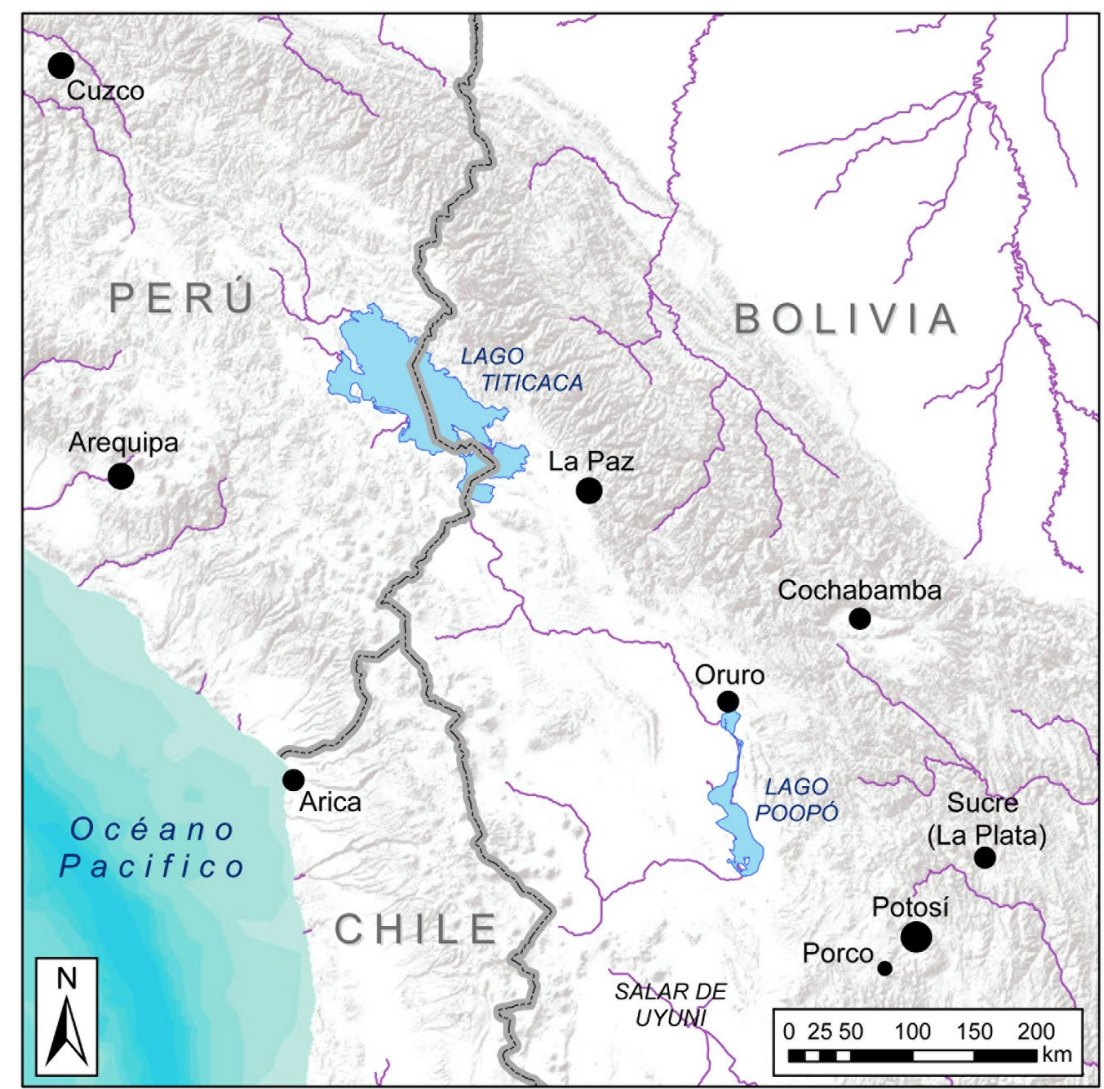

Figura 1. Ubicación de Potosí y Porco en relación con otros lugares importantes de los Andes coloniales (Mapa por B. Waever).

yanaconas, que estaban atados a individuos españoles - trituraron, fundieron y refinaron plata a finales del siglo XVI, utilizando una combinación de tecnologías indígenas y españolas. Más adelante, examino algunos hallazgos arqueológicos y etnohistóricos producto de este estudio con el fin de abordar los cambios en los papeles y posiciones sociales de los obreros durante el período de transición del Imperio inca a la administración española. También, reflexiono sobre la cambiante relación histórica de Ferro Ingenio con otros sitios en el valle de San Juan en el contexto de la dinámica de la infraestructura social local, regional, y mundial, y la economía política.

\section{Arqueología histórica de Porco}

El Proyecto Arqueológico Porco-Potosí (PAPP), bajo el cual se realizaron las excavaciones en Ferro Inegnio para este estudio, fue establecido en 1995 por Mary Van Buren. Su objetivo era examinar las continuidades y disyunciones en la organización de la mano de obra y tecnología en Porco bajo distintos regímenes políticos con un énfasis particular en los períodos inca y colonial. La investigación arqueológica fue iniciada en Porco, porque, a diferencia de la cercana Villa de Potosí, se sabía que había sido explotada durante la ocupación inca de la región. Desde el inicio del proyecto, se recolectaron datos arqueológicos a lo largo de ocho temporadas de campo de varias duraciones a través de estudios de prospección, mapeo, excavación y observación etnográfica de técnicas metalúrgicas tradicionales. Esta investigación ha vinculado datos de los últimos 500 años en un esfuerzo por conectar procesos políticos y económicos en la región desde el período prehispánico tardío con el presente etnográfico (véase el artículo de Van Buren, número anterior). 
Cuando llegaron los españoles a Porco, una gran parte del interior de Potosí estaba dentro del territorio de los Qaraqaras, miembros de la Federación Charkas, una alianza política libre que ocupaba lo que hoy es el centro-sur de Bolivia y que resistió la conquista incaica (BouysseCassagne 1975; Río 1995). La evidencia arqueológica hasta la fecha no ha identificado una ocupación en el período inmediatamente anterior a la anexión de Porco por Tawantinsuyu en el siglo XV (LeCoq y Cespedes 1996, 1997; Van Buren et al. 2006, 2007). En cuanto a los cronistas del siglo XVI, estos se refieren a las minas de Porco como quizás las más ricas del Imperio durante el período inca (Cieza de León 1984 [1553]: 372), y fueron un centro religioso importante para un culto dedicado a la huaca llamada Tata Purqu en documentos coloniales, cuyo cuerpo es el Cerro Apu Porco (Platt et al. 2006: 173).

La prospección y la excavación arqueológica demuestran que el asentamiento inca de Porco no se construyó sobre una comunidad preexistente, sino que consistía en un espacio enteramente planificado, aunque de alcance modesto (Van Buren y Weaver 2012). El entorno construido por los incas consistió en un pequeño centro administrativo (Jalantaña); un complejo con 45 estructuras de almacenamiento (sitio de Huayrachinas); un sitio para refinar plata (Sitio 80), que había sido previamente fundido en huayrachinas cercanas u hornos de viento (Huayrachina Alta); dos complejos residenciales al pie del cerro Huayna Porco (Uruquilla y Cruz Pampa); y el santuario en la cumbre de Apu Porco (Fig. 2). El carácter estacional del trabajo metalúrgico significó un movimiento constante entre las comunidades sujetas y el centro minero, lo que resultó en una gran afluencia anual de personas procedentes de provincias lejanas. La gama limitada de materiales recuperados arqueológicamente sugiere una ocupación temporal centrada en actividades específicas relacionadas con la minería, en lugar de un asentamiento permanente por parte de colonos movidos por el Estado desde otra parte del Imperio. El registro documental indica que estuvieron entre ellos lupaqas (de la cuenca occidental del Titicaca) y carangas (del suroeste del Lago Poopó) (Van Buren y Weaver 2014). El asentamiento incaico de Porco, aunque temporal y estacional, habría adquirido un carácter único y cosmopolita. Con una población nativa muy limitada en las cercanías, el Estado inca habría llevado a trabajadores mit’a y yanakuna de varias partes del Imperio juntos en un espacio ocupado temporalmente.

En sus primeros años como un pueblo español, la riqueza de Porco atrajo gran interés y había hasta 100 casas de españoles (Capoche 1959 [1585]: 125). Sin embargo, hacia 1600, como la notoriedad de Potosí creció, el número de españoles en Porco declinó y dejó solo unos 30 vecinos (Ocańa 1969 [1608]: 182). Las rentables minas de Porco fueron trabajadas principalmente con mano de obra asalariada y coaccionada de indígenas, y complementada por africanos esclavizados (Presta 1992, 1999, 2000: 160). Los primeros trabajadores calificados coloniales fueron proporcionados a través de la institución del yanaconaje (Weaver 2008: 118-120). El sistema requería un gran número de trabajadores con relativamente poca especialización, organizados en pequeños equipos bajo la supervisión de los yanaconas.

Con la llegada de los españoles, el paisaje de Porco experimentó una reorganización radical. El pueblo de Porco incaico consistió en varios grupos de sitios domésticos en la base de las colinas Apu y Huayna Porco, mientras que pueblo español reprodujo un núcleo urbano alrededor de una plaza central. En contraste con la administración española, la producción inca fue organizada por diferentes tareas realizadas por distintas categorías de trabajadores (Van Buren y Weaver 2012: 86). Bajo los españoles, esta forma de compartimentación dio paso a sitios de producción redundantes que reutilizaron la infraestructura inca. La evidencia arqueológica sugiere que casi cada edificio construido durante el período incaico fue reutilizado. Las excavaciones del PAPP en Uruquilla, Cruz Pampa, Jalantańa y Huayrachinas descubrieron restos domésticos, así como rasgos $\mathrm{y}$ artefactos asociados con la producción de plata. El único sitio nuevo establecido en el Período Colonial Temprano en la vecindad del pueblo español era Santiago, un complejo construido al pie de Hundimiento, la vena primaria explotada en ese momento. Las excavaciones en Santiago realizadas durante la temporada de 1999 revelaron una serie de habitaciones rectangulares que rodeaban un patio central, que probablemente fue utilizado para almacenar minerales y equipo. 


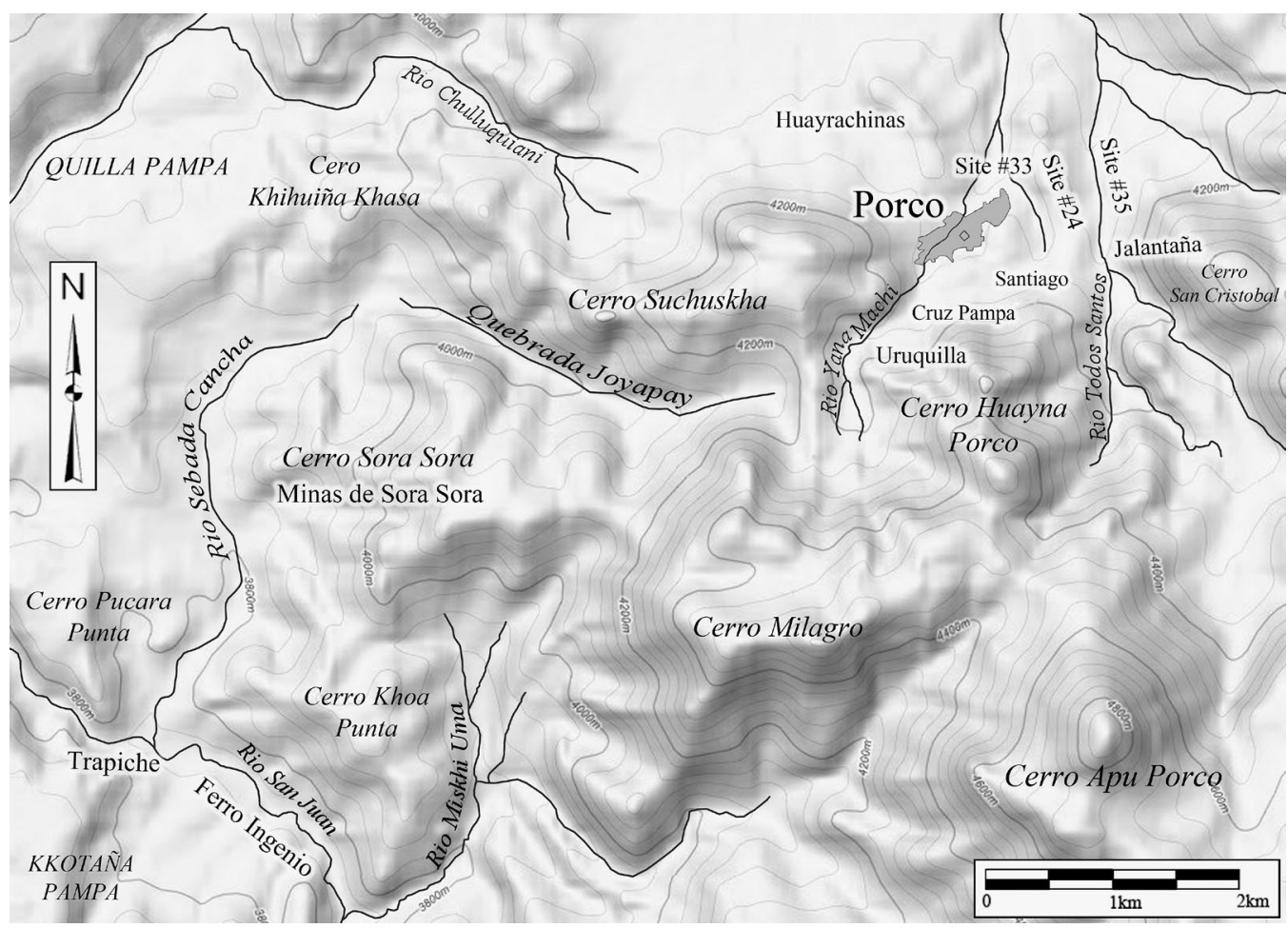

Figura 2. Mapa de sitios coloniales en la región de Porco, incluyendo la ubicación de los sitios de Ferro Ingenio, El Trapiche de San Juan y las minas de Sora Sora (Mapa por B. Waever).

\section{Ferro Ingenio: Una refinería colonial de plata}

El sitio de Ferro Ingenio, ubicado a unos 3900 metros sobre el nivel del mar, se extiende por más de 400 metros a lo largo del río San Juan, e incluye restos de varias estructuras residenciales e industriales: hornos, canales, tinas de lavado, depósitos, un patio y un molino, todos ellos relacionados con el beneficio de la plata (Fig. 3). Las excavaciones y el estudio arquitectónico en el sitio indican su uso en múltiples ocupaciones, consecuencia de la evolución de las circunstancias políticas, económicas y tecnológicas. Aunque hay varios momentos de uso intermitente, reutilización y abandono, el sitio cuenta con dos principales ocupaciones coloniales. La primera ocupación colonial data de finales del siglo XVI y principios del XVII. Esta ocupación temprana parece haber seguido las tendencias más amplias en Porco del uso estacional por una clase de trabajadores calificados, probablemente yanaconas, atada por obligaciones del tributo a los españoles particulares. Estos trabajadores trituraron y refinaron el mineral de alto grado utilizando tecnologías metalúrgicas indígenas. La segunda ocupación principal de Ferro Ingenio ocurrió a mediados del siglo XVIII con la construcción de un gran ingenio. La producción de plata disminuyó en el siglo XVII, pero el cambio en la política fiscal española del quinto al diezmo en 1736 fue el catalizador probable para la reapertura de las minas de Sora Sora y el ingenio para triturar minerales de menor calidad.

Las excavaciones que realicé por PAPP en el año 2007 se concentraron en la parte sureste del sitio, donde la cerámica de superficie, ubicada entre las bases de las estructuras visibles en una terraza aluvial estrecha a un lado del río, sugirió una ocupación del período colonial temprano. Un total de diecinueve pozos fueron excavados en esta parte del sitio. La fase más temprana de ocupación, fechada por la cultura material —incluida una moneda (Po-153) acunada en Potosí durante el reinado de Felipe III (1596-1612) (Menzel 2004: 266)—, coincide con el período 


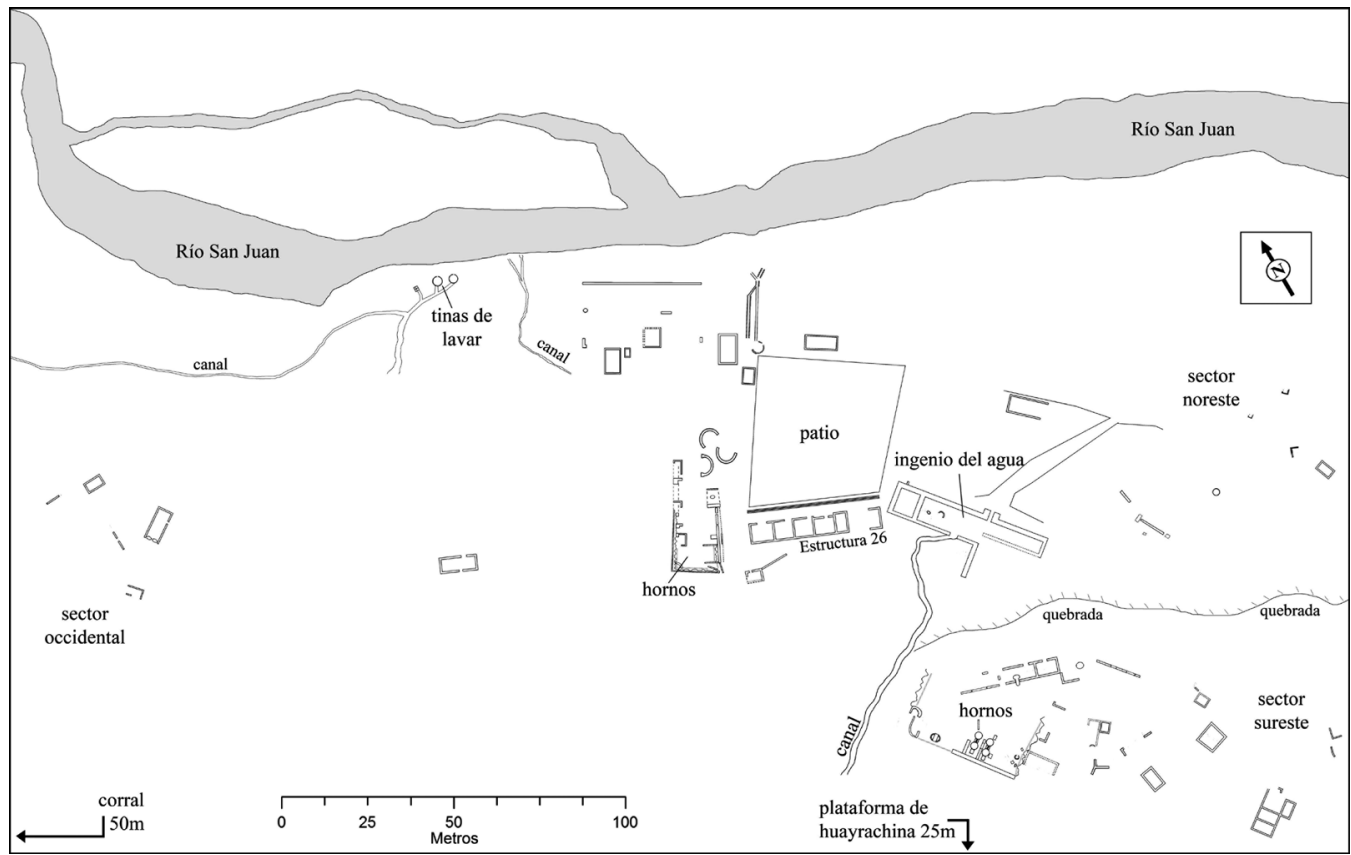

Figura 3. Plano del sitio de Ferro Ingenio (Plano por B. Weaver).

inicial de explotación de las minas de Sora Sora en la cuesta que está en el lado opuesto del río. $\mathrm{La}$ «veta de los zoras», del cerro Sora Sora, es descrita en 1585 por Luis Capoche, un vecino rico de Potosí, como «nueva y espérase de ella mucho provecho» (1959 [1585]: 126). A fines del siglo XVI, muchas reclamaciones se habían concedido a los derechos mineros de Sora Sora a individuos y compañías, entre ellos, la familia de Alonso Zora², indígena y descubridor de la veta.

Cercana a esta primera zona industrial del sitio, existe una un poco más tardía, cortada de la colina para formar un espacio protegido de los vientos del crudo invierno. En este refugio de tierra excavada, se encuentran los restos de varios hornos y un área compacta donde los trabajadores probablemente trituraron a mano el mineral con una gran piedra de molienda que se conoce como «quimbalete». Justo al norte, hay otro complejo de edificios, probablemente, más tardío en el tiempo, y, finalmente, el Ingenio. El Complejo del Ingenio incluye una serie de dependencias, un patio utilizado en el proceso de amalgamación con azogue para refinar el mineral triturado, una sucesión de canales y tinas de lavado, y hornos para calentar el producto amalgamado para producir plata pura. A juzgar por los artefactos y restos arquitectónicos, el molino habría sido construido alrededor de mediados del siglo XVIII. Muchos escritores del siglo XVI han comentado que la plata de Porco fue de una calidad igual o superior a la de Potosí, pero tenía la tendencia a inundarse debido al alto nivel freático (v.g., Capoche 1959 [1585]: 124-125; Bakewell 1988: 73-74). El metal de plata de alto grado no tiene por qué ser tan finamente triturado y se puede fundir con plomo. La amalgamación con mercurio y la tecnología del ingenio fueron desarrolladas para refinar mineral de calidad inferior, y fueron usadas por primera vez en Potosí en la década de 1570. Esto ayuda a explicar por qué el ingenio y el proceso de amalgamación con mercurio, que fue capaz de hacer de la refinación del mineral de calidad inferior una actividad rentable, no se presentó en Ferro Ingenio hasta los medios del siglo XVIII, mientras que, en Potosí, los ingenios ya estaban jugando un papel importante en la producción de plata durante la época toledana. 


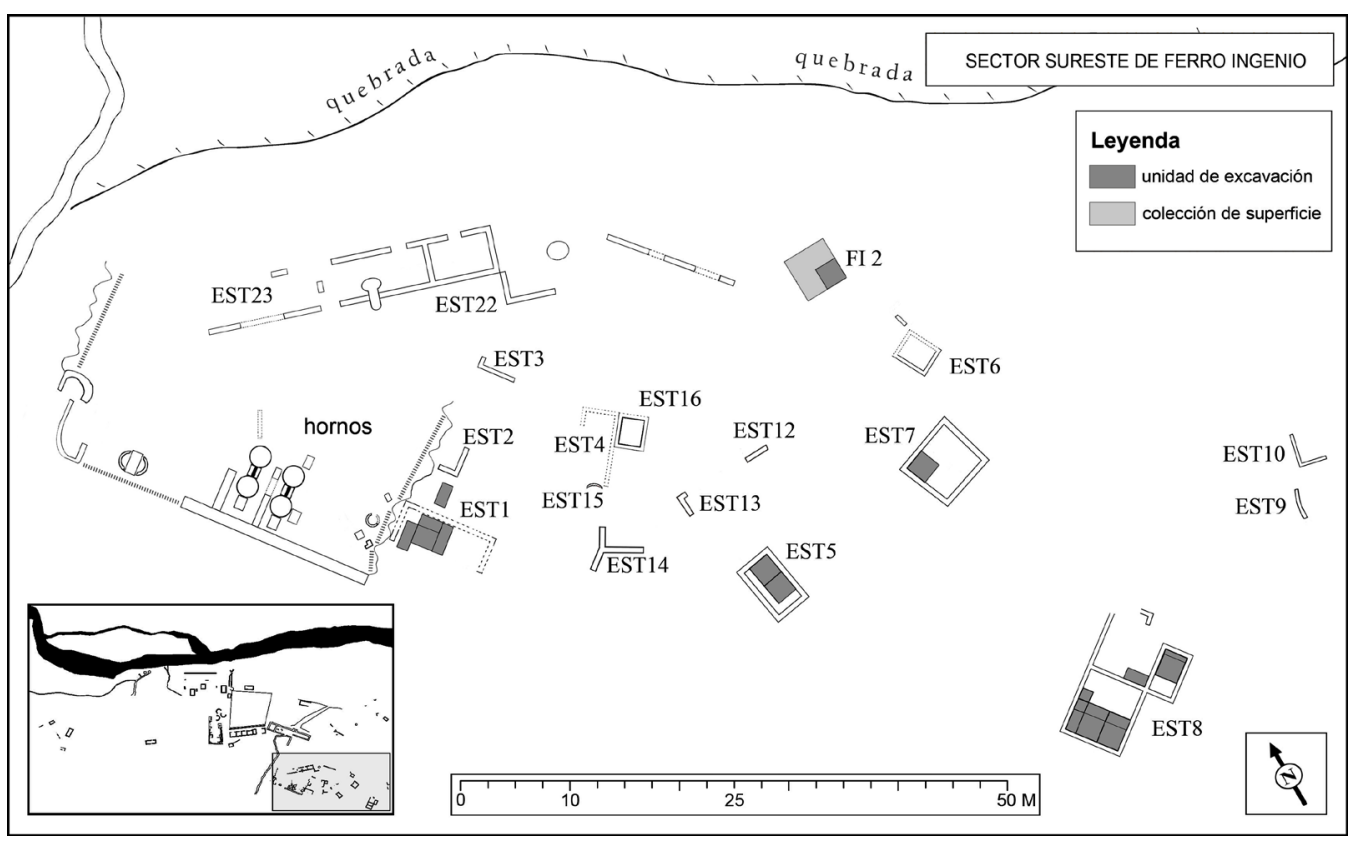

Figura 4. Plano del sector sureste de Ferro Ingenio (Plano por B. Weaver).

\section{El contexto arqueológico}

Los 19 pozos excavados en el sector sureste del sitio abarcaron 53 metros cuadrados (Fig. 4). Los depósitos fueron poco profundos en todo el sitio y, por lo general, carecían de estratigrafía compleja, con una profundidad promedio de 23,4 centímetros. De las 15 bases de estructuras visibles en parte de la superficie del sector más temprano del sitio, cinco estructuras fueron excavadas parcialmente (Estructuras 1, 5, 7, y 8) junto con un basural. Estos contextos proporcionaron mucha información sobre la cronología del sitio, la organización del trabajo y los modos de vida en Ferro Ingenio.

La Estructura 1 se encuentra en el suroeste del sector, junto a otro sector más tardío que contiene un complejo de hornos de copelación en un área excavada en la ladera, que mantuvo protegidos a los hornos. Se colocaron unidades de excavación dentro de la Estructura 1 con el fin de determinar su función y para entender mejor sus límites. Además, para establecer una comparación en este sector del sitio, una unidad fue colocada justo al exterior de la estructura, equidistante (aproximadamente 1,2 metros) de las Estructuras 1 y 2. Considerando que el nivel superficial de la unidad exterior produjo una colección de cerámica de igual concentración que muchas otras áreas del sitio (689 gramos de cerámica), los niveles subsecuentes presentaron mucho menos (ocho tiestos en el Nivel 1 y cinco tiestos en el Nivel 2). Sin embargo, la cantidad de desechos y escoria metalúrgicos fue más constante entre la superficie y el Nivel 2 (29 gramos en la superficie, 12,5 gramos en el Nivel 1 y 26 gramos en el Nivel 2), lo que sugiere que este sector del sitio estuvo vinculado a la minería desde su primera ocupación, mientras que la ocupación doméstica probablemente se intensificó hacia el siglo XVII. Los 10,3 metros cuadrados excavados dentro de la Estructura 1 presentaron tres niveles naturales, que llegaron a 20 centímetros por debajo de la superficie. Ello reveló un basural poco profundo junto a una serie de adobes relacionados con rocas y tierra rojiza alrededor de una concentración de tierra blanca, que se trataría de un horno de copelación. El rasgo es muy similar a uno encontrado por Mary Van Buren y Ludwin Cayo del PAPP durante las excavaciones previas en el sitio contemporáneo de Uruquilla en Porco. 
La estructura parece haber estado parcialmente cerrada para poder albergar al horno. La cultura material de este contexto se diferencia de las otras estructuras excavadas en este sector del sitio, porque el material parece estar más relacionado con la función industrial de la estructura que con la basura doméstica, a pesar de haber sido encontrada una considerable cantidad de cerámica europea colonial temprana (botijas y mayólicas) e indígena (jarras lisas, cuencos, y cerámica de cocción, así como chilpe e inca provincial).

La Estructura 5 tiene una ubicación céntrica en el sector sureste. Fue seleccionada para la excavación especialmente porque parecía ser uno de los ejemplos mejor conservados de una base rectangular visible en la superficie. Los muros son reconocibles por sus cimientos de piedra de doble-fila, que forman esquinas rectas que lucen bien hechas. La ausencia de piedras del derrumbe de los muros y la presencia ocasional de adobe sugieren que las bases fueron coronadas por adobes. El edificio es de 3,75 por 6,60 metros y fue excavada casi en su totalidad. El análisis de la estratigrafía de la Estructura 5 muestra que probablemente hubo dos episodios de ocupación distintos, ambos desde el siglo XVI hasta principios del siglo XVII. Un fogón en los estratos más bajos cerca de la esquina noreste de la estructura indica la primera ocupación, mientras que un segundo rasgo de fogón menos formal, cerca de la misma esquina pero en un estrato superior, corresponde a la segunda y más efímera ocupación. Una división de adobe se habría instalado probablemente después de la ocupación más temprana en un intento por dividir las áreas de actividad. En el lado norte de esta división, un rasgo térmico estaría asociado con el refinamiento de plata. Además de un gran número de artefactos domésticos y cerámica, clavos, fragmentos de herramientas de hierro, martillos de piedras y hojas de cuchillos también fueron encontrados. Estos artículos evidencian un contexto que, probablemente, fue el más productivo por ser doméstico.

La Estructura 7 es similar a la Estructura 5, debido a que fue un edificio rectangular con una sola habitación que medía 5,2 por 6 metros. Una sola unidad de dos por dos metros colocó en la esquina noroeste de la estructura. En contraste con la estratigrafía más compleja de la Estructura 5 , que tuvo casi medio metro de profundidad, esta estructura presentó cuatro niveles, en los que se encontró suelo estéril a una profundidad de entre 12 y 40 centímetros. Inmediatamente debajo de la superficie y adyacente a la pared sudoeste, nuestro equipo descubrió una tercera fila de piedras a un lado de la pared suroeste. Esta pared secundaria no fue tan alta como las bases visibles en superficie y pudo haber servido como banqueta. Aunque fueron escasos los artefactos en esta unidad en comparación con la Estructura 5, la unidad fue representativa de ambas actividades, industriales y domésticas. Sin embargo, además de un fragmento de botija encontrado en la superficie, no hubo cerámica de estilo europeo recuperada. La unidad entera presentó una pequeña cantidad de huesos de camélidos (51 gramos) en comparación con otros contextos en este sector. La unidad también presentó sustancias metalúrgicas, escoria, un clavo, fibras de lana de camélido, dos tupu y una hebilla de cobre. La mayoría de la cerámica parece haber sido utilitaria, aunque hubo también varios fragmentos de jarras de estilo inca provincial. El área excavada de la estructura parece que tuvo un uso primario como un espacio de trabajo. Además, un depósito de basura, oscuro y manchado con restos de ceniza en los estratos inferiores, puede haber correspondido a los residuos de un hogar o pequeño horno situado cerca.

La estructura ubicada más al sureste en Ferro Ingenio es la Estructura 8. Esta también es anómala, puesto que parece ser una de las pocas estructuras con más de una sola habitación desde el período inicial del sitio, debido a que cubre un área de trece por nueve metros y se divide en cuatro cuartos separados. Se colocaron unidades de excavación en cada habitación de la estructura que abarcaron un total de 25,86 metros cuadrados, equivalente al 22\% del área total de dicha estructura. Estas excavaciones permitieron la identificación de áreas de actividades especializadas al interior. El primer cuarto fue excavado en su totalidad y presentó tanto contextos domésticos como industriales. Los estratos superiores contuvieron cerámica domestica muy fina (incluidas vasijas inca provincial de alta calidad), cerámica utilitaria, un zapato de cuero de estilo europeo, un fragmento de un cuenco al estilo inca provincial con asa en forma de puma y una borla que consiste de un textil forrado en hilos de plata. Al igual que en la Estructura 7, una sección de 


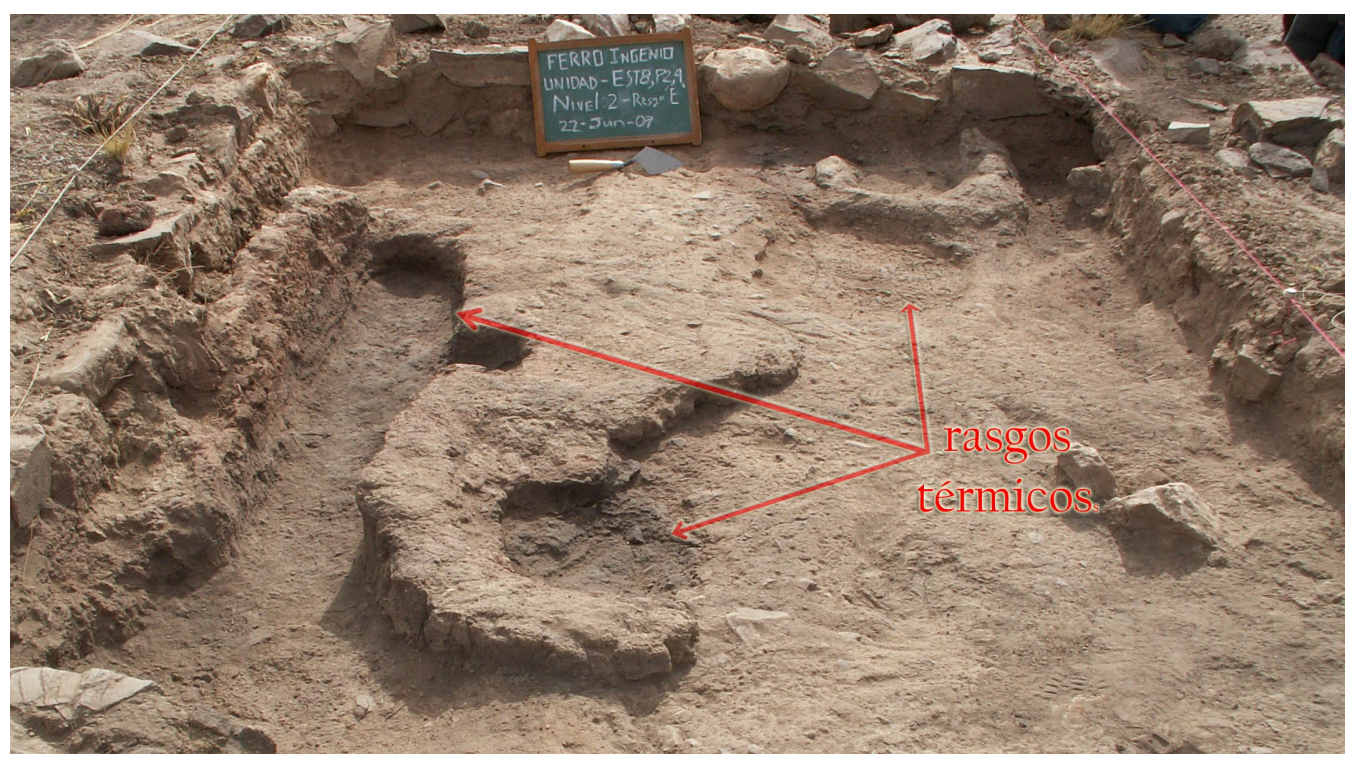

Figura 5. Fotografía del rasgo térmico en el Cuarto “A” de la Estructura 8, en Ferro Ingenio (Foto por B. Weaver).

un muro bajo (posiblemente una banqueta) se encontró a lo largo del muro occidental. En los estratos más bajos, se encontraron desperdicios de hueso animal, vasijas para cocinar y servir, un clavo de hierro y un tupu de plata. Una koncha o fogón se encontró en la banqueta baja y un rasgo térmico muy peculiar fue situado en la esquina noroeste (Fig. 5). Este rasgo térmico consistió en una zanja de forma elíptica hecha de adobe, y ubicada a un lado y a lo largo del muro con un depósito de ceniza gris y arcilla rojiza que la rellenaron. Treinta centímetros hacia el este se ubicó una depresión circular llena de ceniza; y al norte, a un lado del muro norte, otro posible fogón. Adyacente, hubo un gran cuenco colonial con señas de haber sido expuesto al calor. La naturaleza global del rasgo parece haber sido industrial; tal vez, se trató de una técnica para el refinamiento de plata (probablemente, cumplió una función paralela a los hornos de copelación; los grandes hornos de estilo europeo se encuentran en otras zonas del sitio). Sin embargo, los huesos de camélidos y la presencia de ciertas formas de cocción de cerámica en asociación con los fogones parecen indicar que los rasgos térmicos no sirven a un propósito puramente industrial y también podrían estar relacionados con la preparación de alimentos. Dos rasgos, casi idénticos, se encontraron en el Uruquilla y en otro sitio más cerca de Porco. Ambos sitios fueron probablemente contemporáneos a esta parte de Ferro Ingenio y presentaron evidencia abundante de procesamiento de plata, así como de actividades residenciales.

La segunda sala de la Estructura 8 no fue excavada en su totalidad, pero los 1,6 metros cuadrados excavados en el espacio no produjeron ningún rasgo discernible. Tiestos recuperados incluyen botijas, jarras y cuencos rústicos, cuencos hondos, cuencos de estilo inca provincial y cerámica de cocción. Sin embargo, sin ninguna zona de actividad específica, rasgos o patrones que fueron parte de la mezcla del derrumbe de muros de adobes y artefactos, es muy difícil determinar la función del cuarto. Una unidad de uno por dos metros, excavada en el patio central de la estructura, arrojó una variedad mixta de artefactos. Otra unidad fue ubicada en la Estructura 8, que, al parecer, fue un depósito. A nivel superficial, se recuperó una boleadora, fragmentos de mayólica panameńa, cerámica rústica, un fragmento de jarra inca provincial y un fragmento de borde de cuenco lupaqa. Por debajo de estos estratos, el piso de la sala estaba pavimentado en un patrón circular con piedras pulidas. Asociado al rasgo, se halló un frasco para almacenamiento parcialmente completo, fragmentos de cerámica vidriada de plomo blanco, algunos fragmentos de cerámica rústica, 55,5 gramos de huesos de camélidos, una hebilla de metal, una hoja de cuchillo 
de hierro y un clavo de hierro. El piso circular de piedra fue utilizado muy probablemente para proteger los bienes secos, como maíz, papas o posiblemente algún combustible como la takia (excremento de camélido).

Con el fin de obtener una mejor muestra de los tipos tempranos de cerámica y otros artefactos presentes en el sitio, así como para tener una mejor comprensión de las actividades que se realizaron, se excavó un basural ubicado en la zona central del sitio. Se encontró una diversidad de fragmentos de cerámica, incluidos botijas, cerámica con vidriado de plomo, jarras rústicas, jarras y aríbalos del estilo inca provincial, cuencos rústicos, cuencos hondos, cuencos del estilo altiplano tardío, cuencos del estilo chilpe, cuencos del estilo provincial inca, cuencos del estilo lupaqa y cerámica de cocción. Una olla decorada bastante grande y llena de tierra quemada fue recuperada. Esta olla polícroma tiene un diámetro de 24 centímetros en su boca; además, presenta como decoración una serie de cuadrados pintados alternando blancos y negros de manera horizontal alrededor del cuello, y cubre verticalmente a su cuerpo rojizo. La olla se llenó con tierra rojiza y cuatro fragmentos de huesos quemados. Es posible que este rasgo represente solo un patrón del basural, pero también podría ser evidencia de ofrenda ritual o ch'alla. En un contexto etnográfico del siglo XX, Joseph W. Bastien hace referencia a los adivinos kaatan del medio oeste de Bolivia, que efectúan un ofertorio en una olla rota con fuego (1978: 150; véase también Martínez 1987).

En todo el sector sureste de Ferro Ingenio, los elementos estilísticos de la construcción parecen ser muy uniformes, con cimientos bajos hechos de piedra que sirven de apoyo a muros de adobe. Se hace referencia de este tipo de estructura en el siglo XVI como buhíos, y varios documentos coloniales tempranos describen a los yanakuna incas de ese entonces utilizando este tipo de vivienda (Niles 1993: 168). Los muros bajos que fueron encontrados al interior de las Estructuras 7 y 8 pudieron haber servido a una gran variedad de propósitos, pero también es muy posible que fueran banquetas. Desde tiempos precoloniales hasta el presente, las banquetas al interior de las estructuras han sido utilizadas para soportar artículos, especialmente, los vasos cerámicos utilizados para mantener los bienes secos. La Estructura 8, un edificio con salas múltiples, presentó la oportunidad de explorar los contextos industriales, domésticos y de almacenamiento, todo dentro del mismo complejo estructural. La Estructura 5, a la vez que refleja los usos domésticos e industriales, proporciona evidencia para la reutilización y modificaciones estructurales dentro de este período temprano. Por su parte, el probable horno en la Estructura 1 y el rasgo de copelación en la Estructura 8 pueden mostrar distintos métodos tecnológicos del procesamiento de mineral de plata.

\section{Las cerámicas históricas de Ferro Ingenio}

La cerámica recuperada del sector sureste de Ferro Ingenio representa un amplio y diverso conjunto que habla del poder adquisitivo relativo de las personas que trabajaban y vivían en el sitio durante los siglos XVI e inicios del XVII. La cerámica del sitio se puede dividir generalmente en dos categorías distintas de fecha posterior a la conquista española: cerámica del estilo europeo y cerámica indígena. La distinción entre estas dos categorías puede ser realizada basándose en el estilo y la tecnología.

La cerámica europea ha sido elaborada con torno, e incluye mayólica, botijas y cerámica vidriada. Los artículos de estilo europeo, aunque representan una amplia gama de tipos de cerámica, constituyen una parte muy pequeña del conjunto en solo 4,8\% (201 tiestos) de la suma total y $10,5 \%$ (5494,5 gramos) respecto al peso total. La mayoría de ejemplares de cerámica europeas son botijas: un total de 114 tiestos $(56,7 \%)$. Las botijas, o jarras ibéricas de oliva, no son vidriadas, pero sí hechas a torno, toscas, de barro y con forma de ánfora con un cuello restringido (véase Goggin 1960; Deagan 1987; Marken 1994; Avery 1997; Carruthers 2003). La cerámica española colonial más ubicua fue utilizada en las Américas desde 1500 hasta 1800, y, por lo general, se le encuentra en grandes cantidades en los sitios del siglo XVI y XVII (Deagan 1987: 31 ), por lo cual no es una sorpresa que las botijas constituyan una gran porción de la cerámica no indígena en Ferro Ingenio. 
Las mayólicas de distintos tipos y estilos constituyen la segunda más grande categoría de cerámica europea vidriada con plomo, seguida por la cerámica vidriada con barniz de plomo blanco, verde y claro. Tres fragmentos de porcelana china de alta calidad también fueron recuperados del sitio. Cabe anotar que los ejemplos de la mayólica recuperada del Ferro Ingenio se asemejan a las formas típicas desde mediados del siglo XVI hasta los principios del siglo XVII. Estas escudillas o cuencos poco profundos son conocidos en la literatura en inglés como brimmed plates, y tienen bordes planos o convexos. Mucha de la mayólica temprana fue de estilo panamá liso, producida en Panamá desde 1575 hasta 1650 (Rovira 1997). Un tiesto de San Luis azul sobre blanco, cerámica de barro fino producido desde 1550 hasta 1650 en la ciudad de México, también fue encontrado, lo que indica la amplitud del acceso al mercado que poseyeron los habitantes del Ferro Ingenio temprano. Al respecto, el acceso a mayólica en general ha sido interpretado por los arqueólogos como representación de riqueza y estatus (Deagan 1974, 1987; Jamieson 2000, 2001, 2005). En cuanto a Ferro Ingenio, debe considerarse que cuenta con una amplia variedad de mayólica panameña, pero ninguna mayólica local andina ha sido identificada, al igual que las excavaciones en la residencia colonial temprano de elite en Tarapaya, cerca de Potosí (Van Buren 1999: 116-118).

La cerámica hecha a mano mediante tecnología y estilos indígenas constituye la gran mayoría de los tiestos recogidos de Ferro Ingenio, un total de 4024 tiestos $(95,2 \%)$, con un peso de 46,937 kilogramos $(89,5 \%)$. Una pequeña porción de esta cerámica fueron copias indígenas de cerámica europea, pero, usando técnicas alfareras indígenas, y con las fuentes de arcilla y temperantes locales. La gran mayoría de estas son jarras rústicas (2037 tiestos) o cerámicas de cocción (1393 tiestos). Ochenta y cuatro fragmentos de cuerpos de jarras llevaron algún tipo de decoración y 54 de ellos parecen representar un estilo inca provincial local. Muchos de los tiestos de jarra, tanto lisos como decorados, parecen representar fragmentos de vasijas similares al aríbalo incaico. Las formas de cuencos son diversas y están representadas por categorías como liso (231 tiestos), inca provincial (34 tiestos), chilpe ( 44 tiestos), altiplano tardío (48 tiestos), y otros artículos que se parecen a motivos y estilos del inca provincial de la cuenca del lago Titicaca, en particular de las etnias lupaqa y paqajes (28 tiestos). También, hay 68 bordes de cuencos hondos, y un pequeño número de adornos de cerámica, tamices de cerámica, una mufla de cerámica y ruecas de cerámica.

La cerámica inca provincial recuperada de Ferro Ingenio consiste en una mezcla de elementos comunes del estilo cuzco conocidos de otras ocupaciones incaicas y coloniales tempranas, así como varios elementos locales únicos (Fig. 6). La cerámica inca imperial, ya sea en la región de Cuzco o en las provincias, exhibe un carácter relativamente uniforme, y representa un número limitado y repetitivo de formas y estilos decorativos (Kroeber 1952; Fernández 1971; Morris y Thompson 1985; Rowe 1944), aunque modificaciones menores a estos estilos se han hallado en contextos locales (Julien 1983). En Ferro Ingenio, las jarras y cuencos del estilo inca provincial representan una amplia variedad de pastas con temperantes poco visibles, un cuerpo de color amarillo rojizo (5 YR 6/8) y decoración pintada de negro. Sin embargo, algunas jarras, cuencos y ollas tienen motivos polícromos con decoración pintada en blanco, negro y rojo. También, fue recuperada una jarra con una cara antropomórfica moldeada en el cuello y enmarcada por dos líneas estilizadas rojas.

Algunos de los cuencos de estilo inca provincial de Ferro Ingenio llevan una semejanza a los descritos por Stig Rydén (1947) a partir de sus investigaciones tempranas sobre los sitios incaicos tardíos y coloniales tempranos del sur de la cuenca del lago Titicaca. Sin embargo, en Ferro Ingenio, parece que hay una ausencia total de cuencos medio-esféricos con el motivo «llamita» y «asa de pájaro», tan común en las excavaciones de Rydén. La decoración inca sobre los cuencos poco profundos y platos en Ferro Ingenio comúnmente presenta bandas negras alrededor del borde, seguidas por un motivo anular de triángulos, y una serie de bandas o líneas paralelas de espesor variable (tiesto «g» de Fig. 6). Dos ejemplos únicos de asas de platos incaicos fueron recogidos del sitio. Una de las asas tiene la forma de un felino antropomórfico (tiesto «a» de Fig. 6), mientras que la otra tiene la forma del extremo distal de un metatarso de camélido y es muy similar a un tiesto descrito por Rydén. 


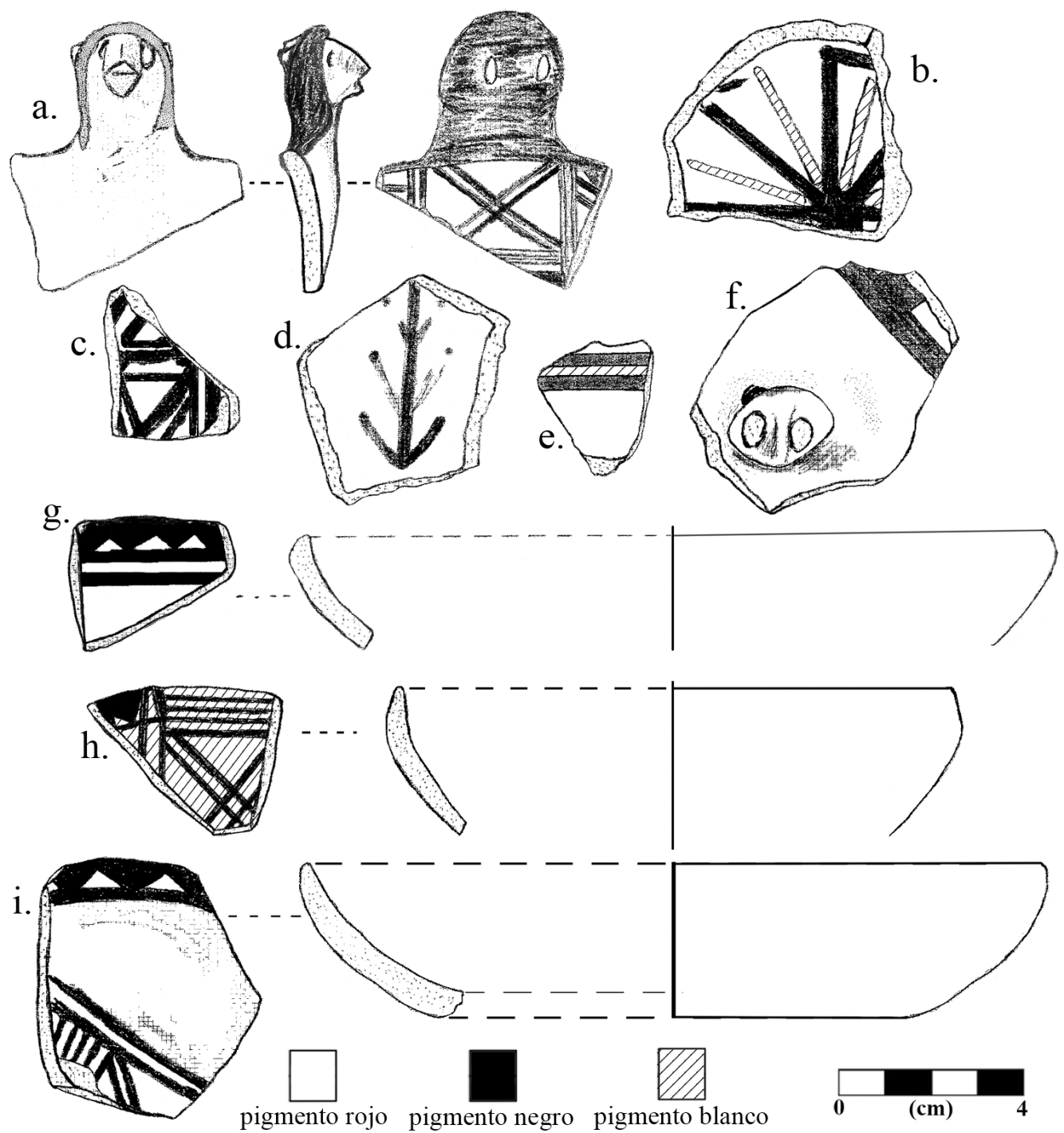

Figura 6. Cerámica Inca Provincial encontrada en Ferro Ingenio: (a.) asa felino de escudilla, (b.) escudilla policroma con motivo "molinete," (c.) escudilla negra sobre roja, (d.) escudilla con motivo "collar," (e.) jarra policroma, (f.) jarralaribalo con adorno, (g.) escudilla policroma del estilo Inca-Lupaqa, (i.) escudilla negra sobre roja (Dibujos por B. Weaver).

Algunas jarras presentan un motivo aún no identificado en otros sitios contemporáneos y que puede representar un fenómeno local en el Período Colonial Temprano. He designado a dicho el estilo como chekan muyu, que significa "línea-círculo» en quechua. Dicho estilo consiste en segmentos de líneas negras pintadas horizontal y verticalmente de manera que se cruzan, a los que se superponen una serie de puntos de diferentes tamaños (Fig. 7). Esta cerámica también se ha encontrado en otros sitios alrededor de Porco, pero su rango completo fuera de Porco no es conocido aún. Mientras que los motivos de estilo inca provincial adornan los cuencos poco profundos y platos de la colección, el motivo chekan muyu solo aparece en jarras. Las décadas inmediatamente después de la conquista espańola de los Andes fueron transformativas en todos los aspectos de lo social y muchas de estas reconfiguraciones pueden verse en la cultura material como la 


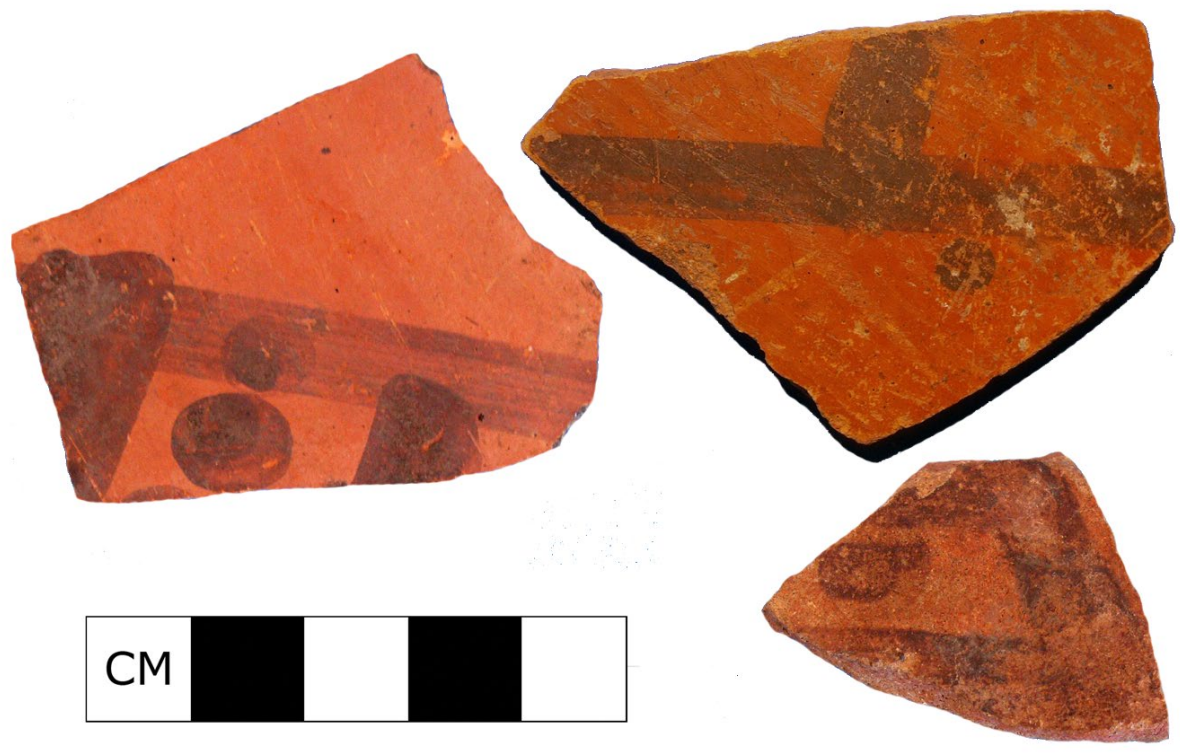

Figura 7. Tiestos de Chekan Muyu (Foto por B. Weaver).

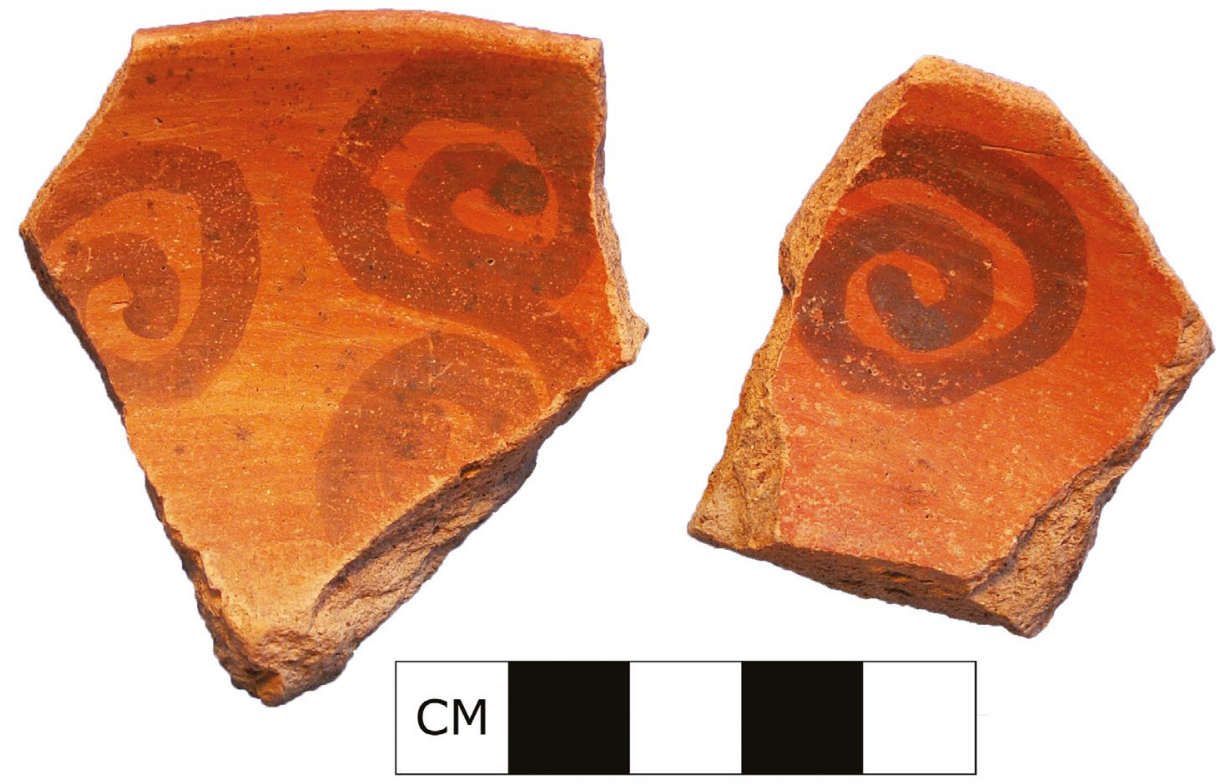

Figura 8. Tiestos de Chilpe (Foto por B. Weaver).

cerámica: los artesanos se basaban en la contemporaneidad, lo preinca e las influencias extranjeras para crear una nueva estética colonial ${ }^{3}$. Aunque los antecedentes prehispánicos de chekan muyu no se conocen, parece que este estilo ejemplifica este proceso estético-político creativo.

Una pequeña porción $(18 \%)$ de los fragmentos de cuencos decorados parece ser cerámica típica de la región Lupaqa del Horizonte Tardío, al suroeste de la cuenca del lago Titicaca. Estos 28 
tiestos representan una variedad de motivos y decoraciones típicas de vasijas inca-chuquito, como documentan varios arqueólogos que trabajan en los Andes sur-centrales para contextos incaicos tardíos y coloniales tempranos (Tschopik 1946; Hyslop 1976; Julien 1983; Van Buren 1993: 254-263). La pasta de estas cerámicas es variable dentro de las normas que otros arqueólogos han reconocido para este tipo de cerámica — tiende a ser rosada (2,5 YR 6/8) o roja (2,5 YR 4/8) — y el temperante es muy fino con muy pocas inclusiones (véase Tschopik 1946; Hyslop 1976; Van Buren 1993).

Un cuenco decorado común en Ferro Ingenio es del estilo chilpe, lo que representa el 29\% de los tiestos de cuencos decorados (Fig. 8). Chilpe se distingue por su pasta roja con fino temperante de arena, pocas inclusiones visibles, el cuerpo de color rojo claro (2,5 YR 6/8), y espirales negros y remolinos. Estos espirales y remolinos están generalmente en forma de «S», pero en ocasiones aparecen como una sola espiral. Los cuencos chilpe en Ferro Ingenio probablemente vinieron de los talleres de cerámica chilpe del siglo XVI cerca de Potosí, identificados por Pablo Cruz (comunicación personal 2006).

La cerámica altiplano tardío constituye un grupo de vasijas indígenas de Ferro Ingenio que no parecen pertenecer a ninguna otra categoría. La mayoría tiene decoración de color negro sobre rojo con una gama de formas no regulares o garabatos. Algunos tienen formas geométricas polícromas en las que se usa el blanco, rojo y negro sobre los cuerpos rojos. Dentro de esta categoría de cuencos y jarras, hay una serie de elementos que parece tener un origen colonial. Algunas de estas vasijas de estilo altiplano tardío tienen ambas características, europeas e indígenas, y, en este sentido, son similares a una clase ${ }^{4}$ de alfarería mexicana colonial del siglo XVI, que incluye un tipo de mayólica gruesa (Lister y Lister 1982; Deagan 1987: 72-73). En particular, hay pocos tiestos de borde que presentan la forma del plato brimmed con bordes anchos y convexos (Fig. 9). Esta forma de vasija presenta una variedad de atributos estéticos. Mientras que algunos están decorados, otros fueron claramente utilitarios y, probablemente, sirvieron en la preparación de alimentos. Julien toma nota de esta forma en la Fase IV de Hatunqolla (1983: 234-236, Plate 42). Rydén, por su parte, describe un tipo de cerámica indígena muy similar con influencia europea y observa los componentes coloniales espańoles en algunos de sus sitios en la cuenca Titicaca, pero, como su experiencia se relaciona con la arqueología precolombina, no profundiza en estos contextos (1947: 285, 300). Otro elemento posterior al contacto identificado por Rydén y que aparece en varias ocasiones en el temprano Ferro Ingenio es una jarra con un adorno de un "garabato» o serpiente en su asa (Fig. 10). Él describe fragmentos «de un mango de cerámica negra, con una línea estrecha, ondulada, y aliviada por el lado superior y externa» (ibid:: 249-250)5.

La cerámica de Ferro Ingenio temprano representa una diversa distribución de estilos y tecnologías, tanto europeas como indígenas. Este corpus cerámico también muestra la variedad de estilos indígenas disponibles en los siglos XVI y XVII en el distrito minero de Potosí de Charcas colonial, en la representación de las formas indígenas y elementos decorativos que siguen mucho después de la Conquista y los nuevos estilos que representan los primeros intentos coloniales de hibridación estilística entre formas europeas e indígenas. El sitio arqueológico de Ferro Ingenio también ofrece un estilo cerámico, chekan muyu, producido en la forma de jarras inca provincial, que nunca antes ha sido descrito. Por otra parte, esta colección cerámica evidencia la amplitud del acceso al mercado y el poder adquisitivo de los habitantes de Ferro Ingenio temprano.

\section{La mano de obra minera del distrito de Potosí y la institución del yanaconaje}

En el siglo XVI, las minas de Porco y Potosí fueron trabajadas por esclavos africanos y un pequeño número de trabajadores asalariados, pero principalmente por mitayos (Bakewell 1984; Cole 1985). Los documentos históricos demuestran el contraste entre la dura realidad de los que trabajaron directamente en la explotación del mineral y la posición más privilegiada de los yanaconas. Estos últimos realizaron un trabajo calificado y su estatus les permitió acumular una modesta riqueza, algunas libertades personales y la movilidad que normalmente no se brindaba 

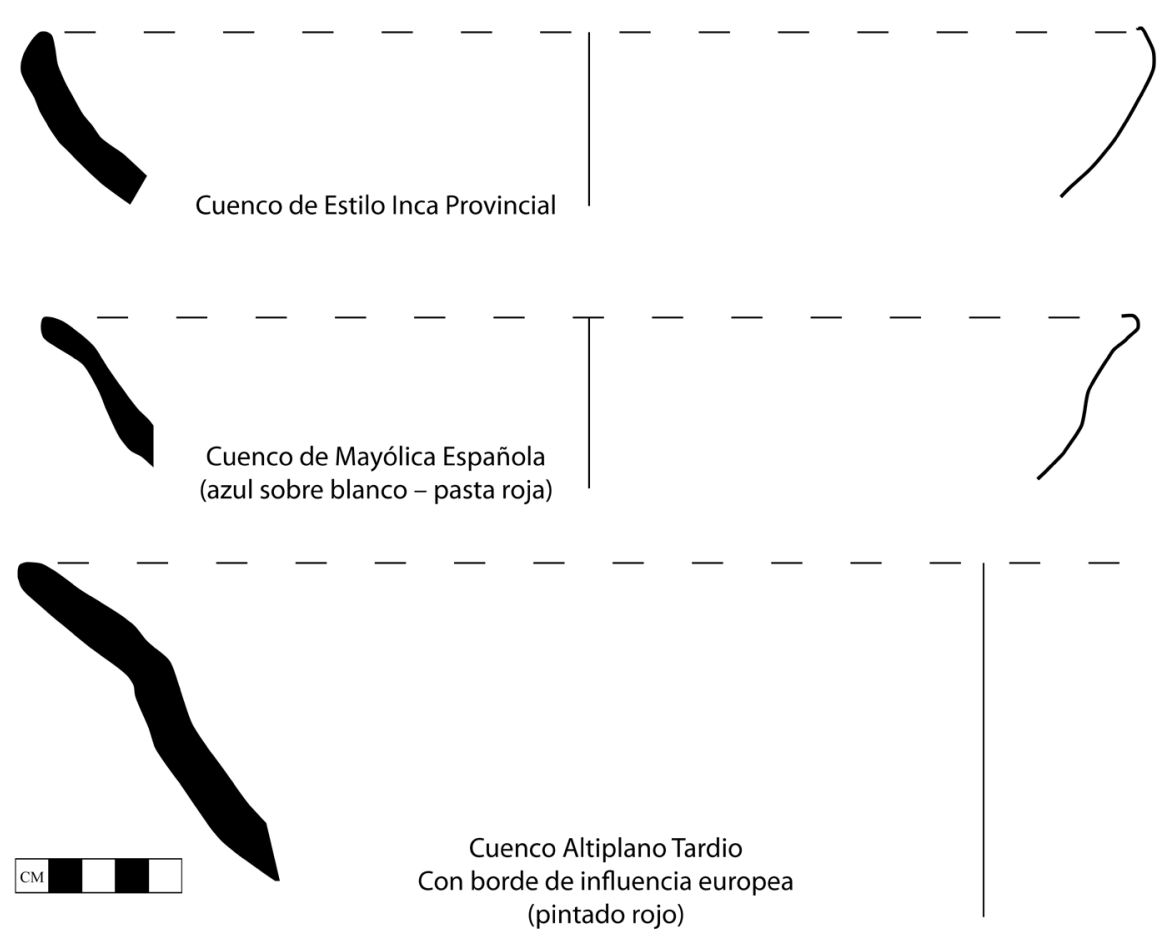

Figura 9. Formas de cuencos encontrados en Ferro Ingenio (Dibujo por B. Weaver).

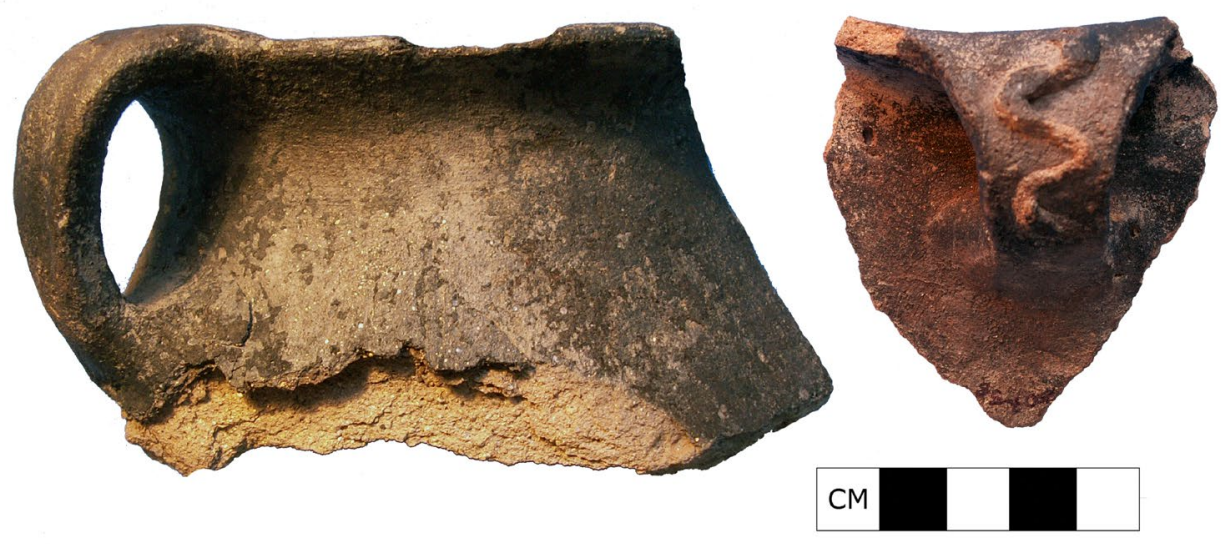

Figura 10. Tiestos de jarras indígenas coloniales con mangos. El tiesto de la derecha tiene un adorno en forma de "serpiente" en el mango (Foto por B. Weaver). 
a los trabajadores indígenas (Bakewell 1984: 34-54). Sobre la base de la evidencia arqueológica, es muy probable que los componentes del sitio de Ferro Ingenio de finales del siglo XVI y principios de siglo XVII fueran ocupados, y trabajados por un pequeńo contingente de trabajadores de esta categoría privilegiada.

Bajo el gobierno del inca, las categorías laborales y el estatus no solo sirvieron para expropiar el trabajo, sino además para asegurar la lealtad provincial al Estado. En el contexto incaico, los términos de estatus de yanakuna, kamayoq y mitima fueron únicos, pero no se excluyeron mutuamente (Julien 1988). Según John Rowe, los yanakuna fueron asignados a la función pública del Estado y no pertenecieron a un ayllu, el estatus de kamayoq fue una posición heredada para realizar trabajo calificado y los mitimaqkuna fueron personas reubicadas en otras partes del Imperio (1982: 96-107; Julien 1982). Debido a que los tres términos fueron únicos y no excluyentes entre sí, un yanakuna también podía ser un kamayoq y/o un mitima; es decir, habría sido un obrero calificado sin pertenecer a la estructura del ayllu, con posición hereditaria y que habría servido al Estado como reubicado en otra parte del Imperio. Al parecer, durante la época colonial española, el sentido propio de estos términos se combinó en el concepto singular de yanacona.

Para entender mejor la evolución del concepto de yanaconaje en el siglo XVI, presento un censo $^{6}$ (padrón) ordenado por el virrey Toledo a los yanaconas y sus familias que estuvieron sirviendo en Potosí en 1575 (Weaver 2008: 118-120). Este documento, que contiene información de gran valor etnohistórico, demuestra una conexión entre esta clase de obrero y una economía minera inca, a través del transporte a Potosí de yanaconas que trabajaron originalmente bajo el inca como fundidores - o huayradores - en Porco, fundiendo el metal en huayrachinas (Capoche 1959 [1585]: 110; Matienzo 1967 [1567]: 70; Cieza de León 1984 [1553]: 375; Van Buren y Mills 2005). La evidencia que surge del estudio que presento sobre el desarrollo de los papeles en las categorías laborales que figuran en la tasa toledana sugiere que la institución del yanaconaje en Potosí fue rápidamente diversificada de sus orígenes incaicas después de la mitad del siglo XVI, debido a que la reproducción del grupo cambió de un estatus atribuido a uno logrado. Del mismo modo, no se puede esperar que los trabajadores de Ferro Ingenio temprano tuvieran totalmente sus orígenes por ocupación ni ascendencia en una estructura laboral inca. En el documento de 1575, algunos individuos de tan lejos como México o Nicaragua fueron «convertidos» a yanaconas en Potosí. En Porco, de donde vinieron en 1545 los yanaconas originales de Potosí, estos participaban en la economía minera realizando un trabajo calificado: la fundición y refinación de la plata, principalmente, con las tecnologías indígenas.

El papel y estatus de lo yanacona se reinventaba bajo el gobierno colonial español para servir en un sistema económico diferente al del Tahuantinsuyu. Varios etnógrafos han documentado muchas veces que el modo de producción precede a la creación de un tipo específico de trabajador (v.g. Kondo 1990; Salzinger 2003; Lyon-Callo 2004), pero esto es a menudo un proceso dialéctico entre el individuo y la estructura (Habermas 1981; 1984). Aunque las categorías de mano de obra española tenían por objeto crear trabajadores individualmente responsables en un modelo europeo, la arqueología en Ferro Ingenio demuestra que los obreros especializados elegían patrones de élites indígenas para mostrar su estatus y mantener los modos de vida andinos en lugar de los españoles, a pesar del modo de producción extranjero. Si bien los yanaconas tenían la capacidad de acumular una modesta riqueza, no parecen emular completamente el comportamiento de la élite colonial española, sino que su capital se invierte en formas andinas de estatus simbólico. Por ejemplo, Diego de Ocaña, un sacerdote que vivió 14 meses en Potosí entre 1600 y 1601, cuenta haber visitado la casa de un indio rico de Potosí, Mondragón (Ocaña 1969 [1608]: 198-199). Ocaña se encuentra con este hombre interesante, quien, a pesar de su riqueza y buena casa, llevaba una vestimenta andina y se sienta en una mesa baja en el suelo para comer, con lo cual expresa las semejanzas culturales con los pobres de los pueblos indígenas en lugar de vivir como un mestizo o europeo. 


\section{Los yanaconas de Ferro Ingenio}

La mano de obra en la ocupación de finales del siglo XVI y principios de siglo XVII de Ferro Ingenio fue realizada por trabajadores calificados que vivían en el sitio de manera estacional con sus familias en y alrededor de las mismas estructuras donde manualmente molían y refinaban el mineral de plata mediante las tecnologías andinas tradicionales. Contemporáneamente, trabajadores asalariados indígenas y un gran número de esclavos africanos fueron empleados en los ingenios e instalaciones de procesamiento de plata contemporáneos en Potosí, donde la amalgamación de mercurio se había convertido en el proceso de refinación principal. Sin embargo, durante la ocupación temprana de Ferro Ingenio, antes de la construcción del Ingenio (en el siglo XVIII), el proceso de refinación permaneció en las manos de indígenas trabajadores calificados — muy probablemente, yanaconas - que trabajaban y vivían independientemente de sus amos españoles, y mantenían el control relativo de sus propios medios de producción. Estos mismos individuos también pueden haber supervisado la extracción de mineral por obreros indígenas y esclavos africanos en las cercanas minas de Sora Sora.

La modesta riqueza de los trabajadores calificados (yanaconas) en Ferro Ingenio colonial temprano se deja entrever a través de unos pocos objetos de lujo, como una borla de hilo de plata, siete tupu de plata, pinzas de plata, un zapato de piel de estilo europeo, vasijas inca provincial y una cantidad limitada de cerámica importada, como mayólica panameńa y porcelana china. Esto no implica que los trabajadores fueron capaces de acumular riqueza a escala de los barones de plata de Charcas colonial, sino que estos trabajadores mantuvieron una cierta autonomía y control sobre sus propios medios de producción, que les ofreció los recursos necesarios para diferenciar su estatus del de otros trabajadores. Es visible la manera en que la colección de cultura material de Ferro Ingenio temprano contrasta fuertemente con el sitio de los campos de minería al otro lado del río en Sora Sora. De los pocos artefactos hallados en la superficie, el contexto temprano consistió principalmente en fragmentos de cerámica rústica, botijas y chekan muyu.

Debido a que los objetos inca provincial solamente constituyen un pequeño porcentaje de las cerámicas de Ferro Ingenio, su presencia requiere de una explicación, ya que las vasijas no eran enteramente «locales» y representan el mantenimiento de una tradición imperial mucho después de la disolución del Estado inca. De un total de 2121 fragmentos de jarras encontrados en el sitio, solo 84 están decorados, y, de estas, solo 54 son objetos inca provincial. En el caso de los cuencos, 222 de un total de 453 fragmentos están decorados y, de estos, solo 34 son inca provincial. Sin embargo, la cerámica inca provincial constituye el $66 \%$ de las jarras decoradas y el $15 \%$ de los cuencos decorados. Estas vasijas, junto con el resto de la colección de Ferro Ingenio temprano, indican no solo cierto grado de poder de compra, sino que también reflejan el modo en que los yanaconas negociaban su privilegiada posición en la sociedad colonial para adoptar los adornos de la cultura material de élite tanto indígena como española y diferenciarse de los trabajadores indígenas menos privilegiados.

Aunque las obligaciones laborales y tributarias del yanacona fueron vistas por los españoles a nivel individual, el sitio de Ferro Ingenio ofrece pruebas suficientes de que las responsabilidades de trabajo fueron probablemente compartidas por la unidad familiar, similar a los hogares bajo la administración de los incas. Esto ejemplifica los conceptos andinos de la complementariedad, reparto del trabajo y la responsabilidad familiar. Tres de las cuatro estructuras excavadas en el sector sureste demostraron rasgos y artefactos tanto domésticos como industriales, lo que sugiere que la residencia fue también un lugar de trabajo, por lo que hogares y rasgos de fundición coexisten en las mismas estructuras. Objetos de "género" como ruecas (a veces, utilizadas tanto por hombres como por mujeres), un laurake ${ }^{7}$ de cobre (que es un adorno para el pelo), cuentas y tupu fueron recuperados de los pozos dentro de estas estructuras. Al respecto, el historiador Enrique Tandeter, en una discusión de grupos que compilaban las obligaciones del trabajo de la mita en Potosí en el siglo XVIII, nota que se necesitaba de la ayuda de toda la familia (1992: 42). A pesar del énfasis 
español en la responsabilidad individual, como, por ejemplo, la gran importancia dada a las categorías de la tasa, el sistema laboral no tuvo éxito en la producción de trabajadores individuales.

En cuanto a las mujeres del Ferro Ingenio colonial temprano, estas probablemente integraban el trabajo realizado en el sitio. Mientras que en el presente etnográfico las minas son pensadas generalmente como espacios dominados por los hombres y las mujeres a menudo desempeńan el papel de apoyo de la clasificación de los minerales, no parece existir ningún requisito cultural profundamente arraigado contra la participación femenina en la fundición y el refinado de metal (Van Buren y Mills 2005: 13). Las mujeres, que pudieron haber producido hilados y textiles en el sitio, cuidaron a los niños y prepararon alimentos; también, pudieron haber estado íntimamente involucradas en el proceso de beneficiar la plata. Manos y metates utilizados en la preparación de alimentos pueden haber sido intercambiables en la trituración de minerales de alto grado. Debido a la alta integración de los espacios domésticos e industriales, y a la inclusión de los rasgos térmicos productivos en los espacios habitables, no hay duda de que existe un alto grado de solapamiento de las actividades productivas y domésticas, compartidas probablemente por la familia como la más básica unidad económica. También, se podría especular que, en el pasado profundo andino, las tecnologías de cocina y refinación tuvieron un origen común y parecen estar conceptualmente relacionadas.

\section{Una perspectiva diacrónica de la explotación minera en el valle de San Juan}

Si pasamos a las últimas décadas del siglo XVIII, es posible leer la evolución del paisaje del valle de San Juan como una ilustración espacial de la dinámica de la competencia y la colaboración entre trabajadores y emprendedores en la economía metalúrgica de Porco-Potosí. Los papeles y posiciones sociales de esos trabajadores continuaron para transformarse en relación con los procesos políticos y económicos, locales y mundiales, que prefiguraban la agencia de los trabajadores. Tanto el complejo del ingenio como sus precursores coloniales tempranos en el sitio de Ferro Ingenio representan operaciones formalizadas, que consisten en la inversión de capital en infraestructura y labor. Sin embargo, a no más de un kilómetro por el río, cerca de la confluencia del San Juan y el río Sebada Cancha, están las ruinas de un trapiche, que representa una empresa de procesamiento de mineral en una escala mucho menor. El trapiche y Ferro Ingenio constituyen no solo la variabilidad tecnológica en las prácticas coloniales de refinar la plata y divisiones laborales, sino que también incorporan dos escalas de operaciones industriales en el refinamiento y aprovechamiento del metal de las minas de Sora Sora.

Frecuentemente, los trapicheros fueron mestizos o indígenas mercantes de plata, y este trapiche quizás estuvo en competencia directa con el ingenio río abajo, que probablemente perteneció a un rico emprendedor europeo o criollo (Tandeter 1981, 1992). Mediante el empleo de trabajo manual en los trapiches para moler mineral de calidad superior a través de quimbaletes, la operación continuó siendo flexible, teniendo en cuenta lo que Tandeter refiere como un próspero comercio de plata ilícita o aquella obtenida cuasi-legalmente.

Ferro Ingenio y el sitio del trapiche ofrecen una narración de la competencia local, y los conflictos raciales y de clase. También, es posible leer las tendencias en la economía global en las que Porco y Potosí fueron incorporados, específicamente, en la rentabilidad de la refinación de plata. La arqueología ha demostrado cómo las tendencias en el precio de plata, la disponibilidad y el rendimiento de los minerales de alta calidad y la competencia entre las clases impactaban la utilización estratégica de la mano de obra y la tecnología en estos sitios. Sea o no la minería rentable, dependía no solo del mercado, sino también de la calidad del mineral explotado. Si el mineral de alta calidad era extraído en tiempos de precios moderados, algunos de los minerales de menor calidad no hubieran sido procesados. Si el valor del metal aumentaba, los residuos eran rexaminados para recuperar minerales de baja calidad que valían el esfuerzo de ser refinados. Lo que vemos en el terreno a lo largo del río San Juan y en las minas de Sora Sora es el resultado de la participación de agentes locales en su propio ambiente geológico, a través del acto fortuito 
de la explotación de minerales, así como las limitaciones de una economía de gran alcance. El ambiente construido se complementa con los contornos geológicos y el espacio, y se convierte en el mediador entre escalas múltiples de actividad industrial y de intensidad laboral a través de la agencia de los trabajadores (Van Buren y Weaver 2012).

\section{Reflexiones finales}

El sitio de Ferro Ingenio ofrece una vista en las relaciones sociales complejas, políticas y económicas que actuaban sobre los trabajadores en el período colonial de Porco. Los contextos domésticos e industriales de finales del siglo XVI y principios de siglo XVII muestran cómo los yanaconas mantuvieron una gran parte de las condiciones materiales laborales andinas y de la responsabilidad familiar, a pesar de la insistencia española en el individuo. La colección de artefactos muestra cómo estos trabajadores promulgaron su agencia para negociar su posición única en la sociedad colonial española y para diferenciarse de otros tipos de trabajadores a través del uso de las señales en la cultura material. También, las transformaciones en los papeles y posiciones sociales de los trabajadores son evidentes en los registros contemporáneos de censos y son representativos de la compleja dinámica en juego en la escena mundial. Es importante recordar que más del $70 \%$ de la plata explotada por los espańoles en las Américas provino de Potosí y sus alrededores, en un momento en que Potosí fue la ciudad más grande y más rica del mundo. Porco y Potosí representan la fuente de una riqueza que transformaba las economías occidentales en la escala mundial desde el siglo XVI. Para entender este impacto a nivel local — por ejemplo, cuando nos preguntamos por cómo se organizó el trabajo, y la demanda de metales preciosos-, es necesario comprender su importancia más allá del contexto de la historia andina.

\section{Agradecimientos}

Tengo una deuda de gratitud con muchas personas y organizaciones que han contribuido con la investigación que se presenta en este artículo. Primero, debo agradecer a Mary Van Buren, la directora del Proyecto Arqueológico Porco-Potosí (PAPP), por la oportunidad de trabajar en el proyecto a su cargo, y por introducirme a Porco y Potosí. Agradezco, también, a los miembros del equipo del PAPP, en particular, a los que ayudaron durante las temporadas de campo 2006-2007: Ludwing Cayo, Delfor Ulloa, Jason Bush, Daniel Martínez, Sheiry Vargas, Rosa Villanueva, Edwin Quispe, Julian Viscarra, Luperia Portillo, Pelagia Torrez, Malena Quispe, Maribel Quispe, Janeth Ecos, Lidia Gutiérrez y Ramiro Rojas. También, estoy agradecido por los comentarios y el asesoramiento de mis colegas Mary Van Buren, Ana María Presta, Susan deFrance, Catherine Julien, Ann Miles, Steven Wernke, Abel Traslaviña, Zachary Chase, Parker VanValkenburgh y Meghan Cook Weaver, así como con aquellos comentaristas que revisaron una versión preliminar de este artículo presentado en el Simposio Internacional de Arqueología Histórica en agosto de 2010: Susan Ramírez y Elmo León. Agradezco, de igual modo, al revisor anónimo. Además, debo agradecer a los departamentos de Antropología de Western Michigan University, Colorado State University y Vanderbilt University. El financiamiento para las temporadas 2006 y 2007 del PAPP fue proporcionado por la National Science Foundation y el National Endowment for the Humanities.

\section{Notas}

${ }^{1}$ La mita consistía en un sistema del trabajo rotatorio y obligatorio impuesto a comunidades específicas que proporcionaban una parte de su población.

${ }^{2}$ Aunque no hay disponible más de información biográfica sobre Zora en la documentación existente, es muy probable que el propio Zora fuese étnicamente Sora, un descendiente del señorío 
aymara en la sierra central boliviana cerca de Oruro (véase Río 2005). Hay alguna razón para asociar una pequeńa pero importante minoría Sora en la región de Potosí con la anterior economía minera inca en Porco. El padrón toledano de los yanaconas de Potosí (el documento citado debajo en la nota 5) registra cuatro de las 701 fundiciones como naturales de Sora y, según Capoche, este grupo de yanacona fue trasladado de Porco a Potosí poco después del descubrimiento español del Cerro Rico en 1545 (1959 [1585]: 78).

${ }^{3}$ En mi investigación sobre la esclavitud y los alfareros africanos en el Perú colonial (Weaver 2015, 2016), he utilizado la teoría de la estética por el filósofo Jaques Rancière (1999, 2004, 2010) para explorar cómo surgieron nuevos estilos cerámicos en el contexto colonial español.

${ }^{4}$ La literatura en inglés se refiere a este tipo de cerámica colonial como indígena ware (Lister y Lister 1982; Deagan 1987).

${ }^{5}$ Rydén refiere a la Figura T de su exposición sobre los sitios del Palli Marca, Cchaucha del Kjula Marca y Pucára de Khonkho: A fragment of a handle of black ware, with a narrow, wavy, relieved line on the upper, outer side (1947: 249-250).

${ }^{6}$ El documento está ubicado en el Archivo Histórico de Potosí - Casa Nacional de la Moneda (AHP-CNM), Potosí, Cajas Reales 18 (AHP-CNM.CR18).

${ }^{7} \mathrm{El}$ adorno de forma antropomórfica, con un torso y la cabeza de un ser humano, los brazos flexionados sobre el pecho y la cola ancha de un pez, se aproxima al laurake Tipo I, según lo descrito por Meneses (1991: 37). Casi todas estas figuras, conocidas como «mamilas», parecen tener atributos femeninos y la idea de una mitad-mujer y mitad-pez parece ser similar a la idea europea de la sirena, pero estos laurakes (incluido este que se encuentra en Ferro Ingenio) a menudo tienen otros atributos de pez, lo cual incluye escamas en las porciones de la parte superior del torso o incluso en la cara. Este artefacto ha sido encontrado en ambos contextos, preincaicos e incaicos, en todas las cuencas del Titicaca y Poopó. Se ha encontrado en concentraciones más altas al sur de la cuenca del Titicaca en el departamento de La Paz, en las provincias de Pacajes, Ingavi y Murillo (ibid:: 32-36). Meneses reconoce las características estilísticas tiwanaku de las figurillas y atribuye que su fabricación continúa en el período inca y los Pakasa (Pacajes).

\section{REFERENCIAS}

Assadourian, C. S.

1966 El tráfico de esclavos en Córdoba de Angola a Potosí: Siglos XVI-XVII, Dirección General de Publicaciones, Córdoba.

Avery, G.

1997 Pots as packaging: the Spanish olive jar and Andalusian transatlantic commercial Activity, 16th-18th Centuries, tesis de doctorado, Department of Anthropology, University of Florida, Gainesville.

Bakewell, P.

1984 Miners of the red mountain: Indian labor in Potosi, 1545-1650, University of New Mexico Press, Albuquerque.

1988 Silver and entrepreneurship in seventeenth-century Potosi: The life and times of Antonio López de Quiroga, Southern Methodist University Press, Dallas.

Bastien, J. W.

1978 Mountain of the condor: Metaphor and ritual in an Andean ayllu, West Publishing Company, St. Paul.

Bouysse-Cassagne, $\mathrm{T}$.

1975 Pertenencia étnica, status económico y lenguas en Charcas a fines del siglo XVI, en: D. N. Cook (ed.), Tasa fe la visita general de Francisco de Toledo, 312-328, Universidad Nacional Mayor de San Marcos, Lima.

Capoche, L.

1959 Relación general de la villa imperial de Potosí (edición de L. Hanke), Biblioteca de autores españoles

[1585] desde la formación del lenguaje hasta nuestros días, Atlas, Madrid. 


\section{Carruthers, C.}

2003 Spanish botijas or olive jars from the Santo Domingo monastery, La Antigua Guatemala, Historical Archaeology 37 (4), 40-55. https://doi.org/10.1007/BF03376622

\section{Cieza de León, P. de}

1984 La crónica del Perú. Primera parte [edición de M. Ballesteros], Historia 16, Madrid.

[1553]

Cole, J. A.

1985 The Potosi mita, 1573-1700: Compulsory indian labor in the Andes, Stanford University Press, Stanford.

\section{Deagan, K.}

1974 Sex, status and role in the mestizaje of Spanish colonial Florida, tesis de doctorado, Department of Anthropology, University of Florida, Gainesville.

1987 Artifacts of the Spanish colonies of Florida and the Caribbean, 1500-1800, vol. I Ceramics, Glassware, and Beads, Smithsonian Institution Press, Washington, DC.

\section{Fernández Baca, J.}

1971 Motivos de ornamentación de la cerámica inca-cuzco, Librería Studium, Lima.

\section{Goggin, J.}

1960 The Spanish olive jar: An introductory study, Yale University Publications in Anthropology, Yale University Press, New Haven.

\section{Habermas, J.}

1981 Modernity versus postmodernity, New German Critique 22, 3-14. https://doi.org/10.2307/487859

1984 The French path to postmodernity: Bataille between eroticism and general economics, New German Critique 33, 79-102. https://doi.org/10.2307/488355

\section{Hyslop, J.}

1976 An archaeological investigation of the Lupaqa Kingdom and its Origins, tesis de doctorado, Department of Anthropology, Columbia University, New York.

Jamieson, R. W.

2000 Domestic architecture and power: The historical archaeology of colonial Ecuador, Contributions to global Historical Archaeology series, Kluwer Academic/Plenum Publishers, New York.

2001 Majolica in the early colonial Andes: The role of Panamanian wares, Latin American Antiquity 12 (1), 45-58. https://doi.org/10.2307/971756

2005 Caste in Cuenca: Colonial identity in the seventeenth century Andes, en: E. Conlin Casella y C. Fowler (eds.), The archaeology of plural and changing identities: Beyond identification, vol. 211-232. Springer, New York. https://doi.org/10.1007/0-306-48695-4_10

Julien, C. J.

1982 Inca Decimal Administration in the Lake Titicaca Region, en: G. A. Collier, R. I. Rosaldo y J. D. Wirth (eds.), The Inca and Aztec States, 1400-1800: Anthropology and history, 119-151, Academic Press, New York.

1983 Hatunqolla, a view of Inca rule from the Lake Titicaca region, University of California Publications in Anthropology, University of California Press, Berkeley.

1988 How Inca decimal administration worked, Ethnohistory 35 (3), 257-279. https://doi.org/10.2307/481802

Kondo, D. K.

1990 Crafting selves: Power, gender, and discourses of identity in a Japanese workplace, The University of Chicago Press, Chicago.

Kroeber, A. L.

1952 Great art styles of Ancient South America, en: A. L. Kroeber (ed.), The nature of culture, 289-296, University of Chicago Press, Chicago.

\section{LeCoq, P. y R. Céspedes}

1996 Nuevas investigaciones arqueológicas en los Andes meridionales de Bolivia: Una visión prehispánica de Potosí, Revista de Investigaciones Históricas, 183-267.

1997 Nuevos datos sobre la ocupación prehispánica en los Andes meridionales de Bolivia, Cuadernos 9, 111152.

Lister, F. y R. Lister

1982 Sixteenth century majolica pottery in the Valley of Mexico, Anthropological Papers of the University of Arizona, University of Arizona Press, Tuscon. 
Llanos, G. de

1983 Diccionario y maneras de hablar que se usan en las minas y sus labores en los ingenios y beneficios de los

[1609] metales [edición de G. L. Mendoza y T. Saignes], MUSEF Editores, La Paz.

Lyon-Callo, V.

2004 Inequality, poverty, and neoliberal governance: Activist ethnography in the homeless sheltering industry, Broadview Press, Toronto.

Mangan, J. E.

2003 Prendas y pesos en el Potosí colonial: Colocando las prácticas urbanas en un contexto social, Revista Andina 36, 107-129.

2005 Trading roles: Gender, ethnicity, and the urban economy in colonial Potosi, Duke University Press, Durham. https://doi.org/10.1215/9780822386667

Marken, $\mathrm{M}$.

1994 Pottery from Spanish shipwrecks, 1500-1800, University Press of Florida, Gainesville.

Martínez, G.

1987 Una mesa ritual en Sucre: Aproximaciones semióticas al ritual andino, Hisbol-Asur, La Paz.

Matienzo, J. de

1967 Gobierno del Perú [edición de G. Lohmann Villena], Instituto Francés de Estdios Andinos, Lima. https://

[1567] doi.org/10.4000/books.ifea.3104

Meneses, J. A.

1991 El laurake: Contribución al estudio de la metalurgia circum lacustre, Pumapunku 1(1), 28-50.

Menzel, S. H.

2004 Cobs, pieces of eight and treasure coins, The American Numismatic Society, New York.

Morris, C. y D. Thompson

1985 Huánuco Pampa, Thames and Hudson, Londres.

Niles, S. A.

1993 The provinces in the heartland: Stylistic variation and architectural innovation near Inca Cuzco, en: M. A. Malpass (ed.), Provincial Inca: Archaeological and ethnohistorical assessment of the impact of the Inca state, 145-176, University of Iowa Press, Iowa City.

Ocaña, D. de

1969 Un viaje fascinante por la América hispana del siglo XVI [edición de Fr. A. Álvarez], STVDIVM

[1608] ediciones, Madrid.

Platt, T., T. Bouysse-Cassagne, O. Harris y T. Saignes (eds.)

2006 Qaraqara-Charka: Malku, Inca y rey en la provincial de Charcas (siglos XV-XVII): Historia antropológica de una confederación aymara, IFEA/Plural Editores/FBCB/University of St. Andrews, La Paz.

Presta, A. M.

1992 Juan Ortiz de Zárate: An entrepreneur in sixteenth century La Plata, Charcas (Modern Bolivia), tesis de maestría, Department of History, Ohio State University, Columbus.

1999 Gonzalo Pizarro y el desarrollo de Porco. Patronazgo y clientelismo en un yacimiento charqueño inicial, VI Reunión de Historiadores de la Minería Latinoamericana, 1538-1576, Lima.

2000 Encomienda, familia y negocios en Charcas colonial (Bolivia): Los encomenderos de La Plata 1550-1600, Instituto de Estudios Peruanos, Lima.

Rancière, J.

1999 Disagreement: Politics and philosophy [traducción de J. Rose], University of Minnesota Press, Minneapolis.

2004 The politics of aesthetics [edición y traducción de G. Rockhill], Bloomsbury Academic, Londres.

2010 Dissensus: On politics and aesthetics [edición y traducción de S. Corcoran], Bloomsbury Academic, Londres.

Río, M. del

1995 Estructuración étnica qharaqhara y su desarticulación, en: A.-M. Presta (ed.), Espacios, etnias, frontera: Atenuaciones politicas en el sur del Tawantinsuyu, siglos XV-XVIII, 3-47, Ediciones Asur 4, Sucre.

2005 Etnicidad, territorialidad y colonialismo en los Andes: Tradición y cambio entre los Soras de los siglos XVI y XVII (Bolivia), IFEA/IEB/ASDI, La Paz. 
Robins, N. A.

2011 Mercury, mining, and empire: The human and ecological cost of colonial silver mining in the Andes, Indiana University Press, Bloomington.

Rovira, B. E.

1997 Hecho en Panamá: La manufactura colonial de mayólicas, Revista Nacional de Cultura 27, 67-85.

Rowe, J. H.

1944 An introduction to the archaeology of Cuzco, Papers of the Peabody Museum of American Archaeology and Ethnology 2 (27), 1-69.

1982 Inca policies and institutions relating to the cultural unification of the empire, en: G. A. Collier, R. I. Rosaldo y J. D. Wirth (eds.), The Inca and Aztec states, 1400-1800: Anthropology and history, 93-118, Academic Press, New York.

Rydén, $S$.

1947 Archaeological researches in the highlands of Bolivia, Elanders Boktryckeri Aktiebolag, Göteborg.

\section{Salzinger, L.}

2003 Genders in production: Making workers in Mexico's global factories, University of California Press, Berkeley.

Tandeter, E.

1981 La producción como actividad popular: «Ladrones de minas» en Potosí, Nova Americana 4, 43-65.

1992 Coercion and market: Silver mining in colonial Potosi, 1692-1826, University of New Mexico Press, Albuquerque.

Tschopik, M. H.

1946 Some notes on the archaeology of the department of Puno, Peru, Papers of the Peabody Museum of American Archaeology and Ethnology 27 (3), Harvard University, Cambridge.

Van Buren, M.

1993 Community and empire in southern Peru: The site of Torata Alta under Spanish rule, tesis de doctorado, Department of Anthropology, University of Arizona, Tucson.

1999 Tarapaya: An elite Spanish residence near colonial Potosi in comparative perspective, Historical Archaeology 33 (2), 101-115. https://doi.org/10.1007/BF03374296

Van Buren, M., L. Cayo, D. Ulloa, R. Villanueva y B. Weaver

2006 Proyecto Arqueológico Porco-Potosí: Gestión 2006, manuscrito inédito en Unidad Nacional de Arqueología UNAR, La Paz.

Van Buren, M., L. Cayo, R. Villanueva, S. Vargas, B. Weaver, D. Martínez y J. Bush

2007 Proyecto Arqueológico Porco-Potosí: Gestión 2007, manuscrito inédito en Unidad Nacional de Arqueología UNAR, La Paz.

Van Buren, M. y B. H. Mills

2005 Huayrachinas and Tocochimbos: Traditional smelting technology of the southern Andes, Latin American Antiquity 16 (1), 3-25. https://doi.org/10.2307/30042484

Van Buren, M. y B. J. M. Weaver

2012 Contours of labor and history: A diachronic perspective on Andean mineral production and the making of landscapes in Porco, Bolivia, Historical Archaeology 46 (3), 79-101. https://doi.org/10.1007/ BF03376872

2014 Exigir una diferencia: El uso estratégico de las cerámicas inkas provinciales en el Periodo Colonial Temprano, en: C. Rivera (ed.), Ocupación inka y dinámicas regionales en los Andes (siglos XV-XVI), 247267, Instituto Francés de Estudios Andinos, La Paz.

Weaver, B. J. M.

2008 Ferro Ingenio: An archaeological and ethnohistorical view of labor and empire in colonial Porco and Potosí, tesis de maestría, Department of Anthropology, Western Michigan University, Kalamazoo.

2015 «Fruit of the vine, work of human hands»: An archaeology and ethnohistory of slavery on the on the Jesuit wine haciendas of Nasca, Peru, tesis de doctorado, Department of Anthropology, Vanderbilt University, Nashville.

2016 Perspectivas para el desarrollo de una arqueología de la diáspora africana en el Perú: Resultados preliminares del Proyecto Arqueológico Haciendas de Nasca, Alpanchis 80 (2 semestre, 2012), 85-120. 